Portland State University

PDXScholar

1978

\title{
The resilience of the child as a factor in successful adjustment to permanent placement
}

Lani Maureen McDonald

Portland State University

Follow this and additional works at: https://pdxscholar.library.pdx.edu/open_access_etds

Part of the Family, Life Course, and Society Commons, and the Social Work Commons Let us know how access to this document benefits you.

\section{Recommended Citation}

McDonald, Lani Maureen, "The resilience of the child as a factor in successful adjustment to permanent placement" (1978). Dissertations and Theses. Paper 2744.

https://doi.org/10.15760/etd.2736

This Thesis is brought to you for free and open access. It has been accepted for inclusion in Dissertations and Theses by an authorized administrator of PDXScholar. Please contact us if we can make this document more accessible: pdxscholar@pdx.edu. 
THE RESILIENCE OF THE CHILD AS A FACTOR

IN

SUCCESSEUL ADJUSTMENT TO PERMANENT PLACEMENT

by

LANI MAUREEN MCDONALD

A research report submitted in partial fulfillment of the requirements for the deqree of

MASTER OF SOCIAL WORK

Portland State University

1978 
TO THE OFFICE OF GRADUATE STUDIES AND RESEARCH:

The practicum advisor approves the research report, THE RESILIENCE OF THE CHILD AS A FACTOR IN SUCCESSFUL ADJUSTMENT TO PERMANENT PLACEMENT. presented June, 1978.

APPROVED:

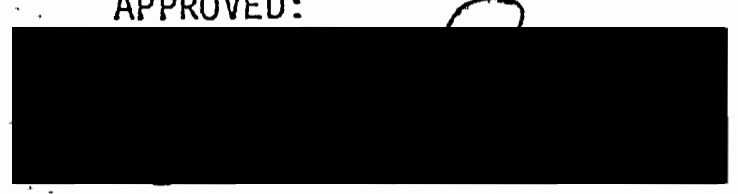

Dr. Arthur Emlen 
FOREWARD

I am pleased to present as an Institute report the following study by Lani McDonald. The report is in partial fulfillment of research requirements for the masters degree in Sociàl Work at Portland State University. While a graduate'student in the School of Social Work, Ms. McDonald also worked for two years as a research assistant on a Children's Bureau supported follow-up study of children who had been returned to their parents or placed for adoption after a period of years in foster homes.*

In that study, which was directed by Janet Lahti, we compared the children who fared well in their permanent placements with those who fared less well. In the process of analyzing the follow-up data we became increasingly aware of a classic problem of interpretation. The extent to which the child's subsequent adjustment reflected individual differences in robustness or ability to cope was inextricably confounded with the events and experiences that came with the placement.

So, Ms. McDonald's interest in assessing individual, constitutional differences, led to this sub-study which was designed to compare those study children most likely to exhibit differences in resilience or vulnerability. It is a nice design, the results of considerable interest, and we are indebted to Lani McDonald for her contribution.

Arthur C. Emlen, Professor

School of Social Work

Director, Regional Research Institute for Human Services

June, 1978.

*Follow-up Study of Children from project "Freeing Children for Permanent Placement" grant \#CB-OCD-481 to the Children's Services Division of the Oregon Department of Human Resources. 


\section{ACKNOWLEDGEMENTS}

I wish to express my appreciation and gratitude to Dr. Arthur Emien and to the future Dr. Janet Lahti for their expertise and counsel. I also want to thank Jim Casciato for running the computer programs and to Dr. Quentin D. Clarkson for his advice and interpretations of the data. I especially want to thank Janet Lahti, Karen Green and Kathie Elsner for their welcomed moral support.

I appreciated the opportunity to study the children of the followup study (Lahti, et al., 1978) and extend my thanks to the project for availing me of the data. 
ACKNOWLEDGEMENTS ........................ $i$...

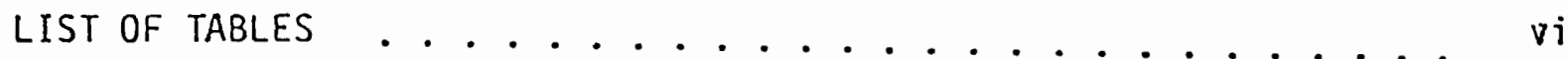

LIST OF FIGURES ................................ vii

CHAPTER

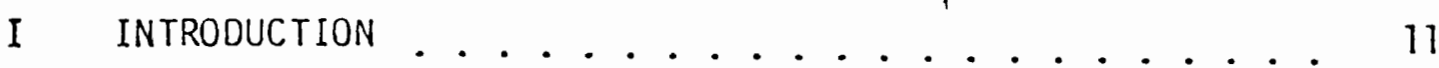

II REVIEW OF THE LITERATURE . . . . . . . . . . 5

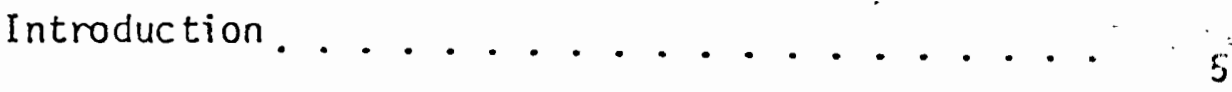

Follow-Up Studies on Adopted and Foster

Children

Adoption

Foster Care

Constitutional Individuality .........

Introduction

Research Studies

Temperament and Vulnerability

Constitutional Individuality and

Physique

Constitutional Individuality and

Summation

Autonomic Balance

Child-Environmental Interplay......... 23

Conclusion . . . . . . . . . . . . . 26

References Cited . . . . . . . . . 28

II METHOD

Sample Selection ............... 35

Data Analyzed ................... 37

Child's Self-Concept Inventory 
Parent Interview and Parent Questionnaire Validating Analys is

Environmental Variables

Summary

IV RESULTS

Child's Self-Concept Analysis . . . . . . . 41

Validating Analysis ............... 46

Initial Status and Heal th Status Analysis . . . 50

Environmental Variables Analysis ........ 51

Socio-Economic Status

Permanency

Sumnary ................. 52

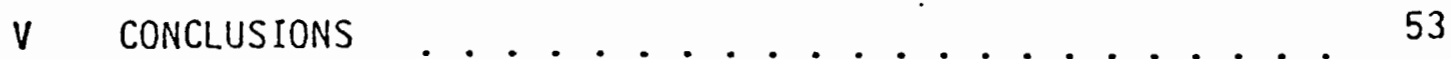

VI BIBLIOGRAPHY OF ADDITIONAL SOURCES CONSULTED . . . . . 57

VII APPENDICES . . . . . . . . . . . . . . . . . . . 61

Appendix A: Placeability Barriers . . . . . . 62

Appendix B: Nineteen Child Self-Concept Question . 65

Appendix C: Stepwise Discriminant Analys is--Function............... 66

Appendix 0: Initial Status, Heal th Status and Child Self-Concept Variables Used for Correlation Matrix . . . . . 67

Appendix E: Permanency Variables . . . . . . 69

Appendix F: Stepwise Discriminant Analys is on

Initial Status Variables ...... 70

Appendix G: Summary of Stepwise Discriminant Analysis on Initial Status Variables . 71

Appendix H: Stepwise Discriminant Analysis on Heal th Status Variables 72

Appendix I: Stepwise Discriminant Analysis on Permanency Variables ....... . 73 
I Post-Placement Adjustment Scores Cross-Tabulated with Caseworker Pre-Placement Rating of the Condition of the Child...........

II Classification of Post-Placement Adjustment Based on Number of Factors on Which Child Scored Above the Mean

III Post-Placement Adjustment Scores Cross-Tabulated with Caseworker. Pre-Placement Rating of the Condition of the Child

IV Stepwise Discriminant Analys is of Child's Self-Concept Variables.................. 42

$\checkmark$ Summary of Stepwise Discriminant Analys is on Child Self-Concept Variables.......... 44

VI Number of Cases Classified Accoraing to Hypothesis...

VII Correlation of Presumably Resilient Child's SelfConcept with Initial Status and Health Variables.................. 48

VIII Correlation of Presumabiy Vulnerable Child's SelfConcept with Initial Status and Health Vari-

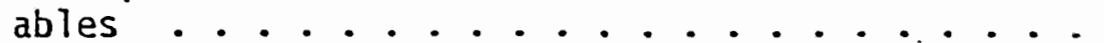

- IX Number of Cases Classified According to Initial

Status Hypothesis ............

$X$ Number of Cases Classified According to Heal th Status Hypothesis ............

XI Number of Cases $\mathrm{Cl}$ assified According to Permanency Hypothesis ............. . ${ }_{52}$ 


\section{LIST OF FIGURES}

\section{FIGURE}

PAGE

1. Variability Accounted for by Discriminators on Child's Self-Concept Analysis . . . . . . . . . 


\section{CHAPTER I}

\section{INTROUUCTION}

The predicament of foster children has been a societal concern and the subject of considerable research and planning. In November 1973, Children's Services Division of Oregon initiated a demonstration project aimed towards finding permanent homes for children they believed were in foster care inappropriately. A follow-up study (Lahti, et al., 1978) of the demonstration project's efforts was conducted in 1976 in order to determine the stability and success of the placements.

The past circumstances of the children had been difficult. Some had incurred abuse and neglect; many had been moved numerous times before permanency pianning was implemented; many had been in foster care longer than considered necessary. Nonetheless, the follow-up status of these children reflected that many had successfully adjusted to their new circunstances: whether adopted, returned to their parents, or by remaining in indeterminate foster care. Why have they made successful adjustments? What facilitated their ability to adjust?

This study explores the hypothes is that constitutional factors were significant in mediating their successful adjustment. The adjustment of children who in the past would have been viewed as permanently scarred and unable to adjust has provided researchers with an idiosyncratic situation that has also been found in other studies: children have adjusted despite odds against it and children considered to have incurred minimal trauma have had difficulty adjusting. 
The theory of constitutional individuality hypothesizes that children differ at birth: some are more active, others passive; some cry more, while others laugh; some are cuddlers, others seemingly rejecting; some are robust, others fragile. Some theorists believe that those children who have an innate propensity to cope with life and its stresses are from the beginning healthier, more active and stronger. The literature on constitutional individuality will be reviewed in Chapter II.

The follow-up study (Lahti, et al., 1978) provided an opportunity to explore the constitutional individuality hypothes is. Although the followup study was not designed to investigate this particular issue, an interpretation of the results can to some extent reflect constitutional factors.

A sub-study of the follow-up project was undertaken. Using data collected by the follow-up study, a design was constructed that attempted to identify within the sample of the follow-up study two groups of children who would reveal differences of a constitutional nature. It was anticipated that these two groups would reflect constitutional traits theorized to represent resilience or vulnerability. Since there was no direct way of identifying resilient or vulnerable children independently of the adjustment they had made to placement, groups were identified in which there was likelihood of traits characteristic of resilency or vulnerability existing.

Children whose adjustment to placement was better than expected were identified as representing the presumably resilient children; those children who did worse than expected represented the presumably vulnerable children. The indicator used to identify children one might expect to do poorly was a pre-placement caseworker rating of the condition of the child explained in Chapter III. The two groups differentiated are illustrated in 
Table I.

TABLE I

POST-PLACEMENT AOJUSTMENT SCORES CROSS-TABULATED WITH CASEWORKER PRE-PLACEMENT RATING OF THE CONOITION OF THE CHILD

Post-Placement Adjus tment

Caseworker Pre-Placement Rating of the Condition of the Child

Low Risk*

High Risk

Poor Adjus tment

Did worse than

expected $n=9$

Good Adjus rment

Did better than

expected $n=19$

*Risk of making a poor adjustment to placement

These two groups of children were expected to exhibit differences of a constitutional nature; this investigation was designed to search for these differences. It should be understood that the follow-up study was not originally designed to test the constitutional individuality hypothesis, however, an interpretation of the results allude to the probability. that factors within the children influenced their adjustment. Though the data collected by the follow-study were not designed to identify constitutional traits in the children, they provided an available source of data. Prime sources of data included a child's self-report (Self-Concept Inventory*), parent interviews and parent questionnaires.

The environment can have a significant impact on an individual's life. Because of this significance, two control variables representing the contribution of the environment were selected: socio-economic status

*Primary Self-Concept Inventory, Developed by: Douglas G. Muller and Robert Leonetti. Austin, Texas: Learning Concepts, 1974 . 
of the placement parents and the assessment of how permanent the placement was perceived to be by the parents and children. Many of the children had moved up in socio-economic status when they were placed and this may have contributed to their adjustment. The follow-up study (Lahti, et. al., 1978) found that the most significant indicator of a placements success was the sense of permanency that prevailed in the home; this seemed an important control variable to test for.

This sub-study endeavors to search for patterns and interpretable differences in two groups of children expected to express characterisi ics considered representative of vulnerability or resiliency. These two groups of children expressed a uniqueness by virtue of contradicting the ratings of their placeability. It seemed likely that this uniqueness of having adjusted better or worse than expected might be reflective of the child's vulnerability or resiliency.

The literature discussing constitutional individuality is presented in Chapter II. The methods employed to analyze the data are covered in Chapter III. The Results are presented in Chapter IV and Chapter $V$ includes the conclusions drawn from the analyses. 


\section{REVIEW OF THE LITERATURE}

The purpose of this literature review is three-fold: (1) To illustrate through follow-up studies on adopted and foster children the differences in their adjustment to placement. These differences give credence to the hypothesis that constitutional factors within the individual influences adjustment; (2) To relay the major research on constitutional individuality; and, (3) To discuss through the literature the interaction of the individual to the environment which has been hypothesized to influence adjus tment.

\section{INTRODUCTION}

When one realizes that thousands of children are placed in out-ofhome care each year, it becomes obvious that life is not a continuous, stable, homogenous experience for many children. Sally Provence reflects:

The human being has considerable capacity for recovery: there is a drive towards health and harmony in development that is part of human development. We must remember, however, that there is such a thing as too much stress, too much deprivation, and the ability to adapt to stress or to recover from deprivation or hurt can be overtaxed. (Talbot, et al., 1971, p. 18).

Children who are placed in out-of-home care provide the opportunity to explore such concerns. Few would deny that children experience some trauma when they are separated from their parents and placed in "care." What the child experiences has been compared to the grief process. Thomas (1967) investigated the grief process in foster children and concluded that they 
do indeed progress through the grief stages of pre-protest, protest, despair and detachment. Although her research focused on foster children, her findings can be generalized to adopted children as well.

Separation and subsequent placement does affect children, but for how long and to what extent separation-experiences influence overall adjustment and whether the effects of these experiences are irreversible, cannot be determined from the short-term studies on familial separation. A thorough examination of the long-term effects is indicated. Recent research on follow-up adjustment of foster and adopted children is challenging past assumptions and is also suggesting that factors within the individual, i.e., constitutional individuality, may be an important determinant of adjustment.

Many variables have been explored as contributing to successful adjustment in foster and adopted children: length of time in care, age at time of placement, socio-economic status of caregivers, and attitudes of the caregivers towards the child. None of these variables, however, appear to be consistent predictors of whether a child will adjust to placement in outof-home care. Some theorists hypothesize that there are factors within the child that have an ultimate effect on adjustment, not only in placement in out-of-home care, but of any crisis or trauma experienced.

\section{FOLLOW-UP STUDIES ON ADOPTED AND FOSTER CHILDREN}

Children placed in out-of-home care are an excellent population to closely observe the effects of familial separation on life adjustment. The major follow-up studies on adopted and foster children were examined with the hope of discovering variability in how children adjusted; if variability occurred, one would need to question whether generalized statements about the effects of familial separation could be postulated as they have been in 
the past. It was expected that ambiguities would be found; this expectation was confirmed.

\section{Adoption}

A number of long-term follow-up studies of adopted and foster children have been conducted since the Sixties. The three primary studies completed have been Seglow, Pringle and Wedge's (1972) research in England, Scotland and Waies; Bohman's (1971) research in Sweden; and Kadushin's (1970) research in the United States.

Seglow, Pringle and Wedge (1972) studied a cross-section of adopted children over four intervals of their first 13-years of life. Comparison groups were comprised of children in the general population who had lived with their biological parents and also illegitimate children who had remained with their biological mothers. The study concluded that at age 7 , the adopted children were equal to or superior to the comparison children in educational attainments, general abilities and physical development. In addition, the adopted children fared better than the illegitimate cilildren who had remained with their mothers; in other words, they had not incurred maternal-separation.

Bohman (1971) studied 492 children ages 10 and 11 in respect to their type of placement. There were three groups. Group I $(n=163)$ were adopted children adopted before their first birthday who had lived in infant homes prior to placement. Group II $(n=205)$ were considered a heterogeneous group in regards to their social environment and background and were living with their biological mothers at the time of follow-up. Approximately one-third of this group had been placed in infant homes prior to being returned to their mothers; the others were "cared for by their mothers from soon after 
birth" (p. 6). Group III $(n=124)$ were adopted and foster children who had no contact with their biological families at the time of follow-up. About half of these children had lived in institutions nine months before being placed, and had been considered hard-to-place due to hereditary factors, disabilities and retarded development.

The adjustment scores of the three groups revealed that in Group I, the boys were definitely maladjusted, $34 \%$ displayed obvious behavioral disturbances, and $44 \%$ were entirely free of symptoms or disturbances. Approximately $11 \%$ of the girls in this groups were.considered to have problems. In Group II, $20 \%$ of the boys were considered problem cases, $26 \%$ had "moderate symptoms," and $9 \%$ of the girls had problems. In Group III, $22 \%$ of the boys and $20 \%$ of the girls were judged to be problem cases; 62 of these children had medical or hereditary handicaps.

Bohman's findings are significant as they exemplify that adjustment outcome cannot be predicted simply on the basis that maternal separationdeprivation has occurred or ameliorated totally by a change in the environment. The three groups had children who exhibited behavioral disturbances or symptoms, and those that were free of them.

Kadushin (1970) studied 91 children considered to be older children by adoption standards; that is, placed for adoption between the ages of 5 and 12 , with the mean age of adoptive placement being 7.2 years. The social histories of these children were marked by deprivation and pathology, nonetheless "The group as a whole,... showed a greater degree of psychic health and stability than might have been anticipated given the nature of their backgrounds and developmental experiences" (p. 208). Kadushin suggests "that children have varying capacities to deal with potentially traumatic conditions and that these strengths enable them, when provided 
with a heal thier environment, to surmount the damaging influences of earlier developmental insults" (p. 219).

Additional studies appearing in the late Sixties and in the Seventies have presented some interesting findings and will be presented (Lahti, et al., 1978; Tizard and Rees, 1974; Jaffee and Fanshel, 1970).

Lahti, et al. (1978) conducted a follow-up study to evaluate the placements of foster children, adoptive children and children returned to their natural parents. The follow-up study was an outgrowth of a demonstration project initiated by Oregon's Children's Services Division which sought to "reduce the backlog of children in indeterminate status by doveloping more permanent al ternatives" (p.1.1).

A two-part study was conducted for the purpose of determining ine stability and type of placements, and to assess the success of the placements through parent-generated and child-generated data collected from interviews with the parents and children.

Some interesting and though provoking information emerged from the study. Parents who perceived the placement as permanent (regardless of whether it was legally or not) had children who were in the higher adjustment groups. The type of placement: adoption, foster care, or being returned to the natural parent, had little bearing on whether the child adjusted or not. A significant finding was that the child's behavior when he or she entered the placement, combined with the health of the child, was one of the best predictors of a child's adjustment at follow-up. A further finding revealed that a child's self-image correlated with his or her present adjustment and heal th status scores.

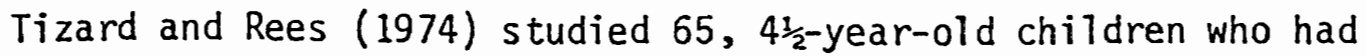
spent their first few years in residential nurseries. At the time of the 
follow-up, 24 of the children had been adopted, 15 had been returned to their natural families, and 26 had remained in institutional care. Intergroup comparisons were made among the three groups and a control group comprised of children in the general population who lived with their natural parents. It was concluded that the adopted children had the highest intelligence scores of all the groups. Of particular interest was evidence that the group of $4 \frac{1}{2}$-year-old children who had remained in institutional care manifested no cognitive retardation. The children restored to their natural parents were found to express poorer adjustment though they were socially as friendly and extroverted as the other children. Tizard and Rees noted that "In exhange for acquiring a mother they had lost some environmental advantages" (Tizard and Rees, 1974, p. 98).

Jaffee and Fanshel (1970) studied one hundred families who had atopted children during 1931 to 1940 . The one hundred children were 3 years of age and under at the time they were adopted. Forty percent of the adoptive families indicated that the adoptees had adjusted as adults. The researchers noted:

A wide range of life adjustments among our one hundred adoptees. Many had manifested remarkably few problems throughout nost of their lives and were currently functioning in this manner. On the other hand,...a number of adoptees had experienced a variety of quite serious problems in growing up, and that some were still contending with major adjustment difficulties at the time their parents were interviewed. (p. 305)

Earlier studies of adoptive children have concluded that the adopted child is more normal than anticipated (Addis, et al., 1954; Borgatta and Fanshel, 1954; Raleigh, 1954; Skodak and Skeels, 1945).

\section{Foster Care}

One of the first "large-scale" follow-up studies of foster children 
concluded that $88 \%$ of 235 foster children had successfully adjusted. Van Thes is states:

Our study of the groups as a whole, insofar as the subjects have demonstrated their ability to develop and to adjust themselves to good standards of living, and perhaps even more strikingly, our study of individual members of it, leaves us with a distinct impression that there exists in individuals an immense power of growth and adaptation. (Van Thesis, 1924, p. 163)

Roe and Burks (1945) conducted a follow-up study of 36 young adults who had been foster children and concluded, "most of these subjects have established reasonably satisfactorily lives," (pp. 382) despite their pathological natural families which were characterized by maltreatment, negi gence, and alcoholism. Roe ana Burks were awed at what seemed to them an expression of "the biological toughness of the human species" (p. 391).

Meier (1965) studied 61 young adults who had spent five years or wiore in foster care and had never been returned home. These individuals had experienced an average number of 5.6 foster-care placements. Meier concluded that the "vast majority of the subjects have found places for themselves in the comunity" (p. 296):

Maas (1969) followed-up 20 young adults who had been in residentiol nurseries in England during the war. He stated,

Although these 20 young adults may have been seriously damaged by their early childhood separation and residential nursery experiences, most of them gave no evidence in young adul thood of extreme aberrant reactions... To this extent the da ta supports assumptions about the resiliency, plasticity and modifiability of the human organism rather than those about the irreversibility of the effects of early experience." (pp. 66-67)

It is rather remarkable when one learns how these children seem to have coped with the most adversive life situations, often subjected to physical and emotional abuse and neglect, being separated from their parents, and reared in socially deprived conditions. What is it about these children 
children that has enabled them to cope and adjust, and what of those children who have been unable to? Are there inherent capacities within the individual that mediates their ability to adapt?

Many variables have been explored as possibly contributing to the adjustment of these children. None, however, seem applicable to all the situations studied or consistent predictors of successful adjustment. Kadushin states that children have. "varying capacities to deal with potentially traumatic conditions" (Kadushin, 1970, p. 219). One purpose of this literature review is to explore the area of constitutional individuality as representing these "varying capacities."

\section{CONSTITUTIONAL IND IVIDUALITY}

\section{Introduction}

Research exploring individual differences in children emerged from the field of psychoanalysis and attempted to examine the plausibility of predicting behavioral disturbances in children from an early age, i.e.. infancy. Systemized observational researci was conducted on infants and young children and substantiated that individual's differ from birth, in measureable ways. Predicting dispositions to behavioral disturbances has nat as yet been as conclusively proven and is still being researched.

Aldrich, Sung and Knop (1945) studied the differences in the amount of crying in infants. Ribble (1944) and Balint (1948) focused on differences in tempo and. intensity of infant sucking behavior. Shirley (1931) and Gesell (1937) noted differences in motor activity as did Escalona, et al (1952) and Fries and Woolf (1953): Jones (1930) studied children's varying responses to frustration. Birns (1965) studied variations in responses to stimulation. Spitz (1946) and Washburn (1929) studied smiling and laughing responses in infants. Considerable research leaves little 
doubt that the human infant is quite a unique creature and expresses constitutional individuality.

When studying constitutional individuality one is impressed with the barrage of theoretical constructs and perspectives. Preadaptiveness, protective barrier, and primary positive response represent only a few of the constructs applied to the study of constitutional differences in individuals. Hartmann (1946) speaks of children having "a certain degree of preadaptiveness." S. Freud (1937) referred to a "protective barrier" against stimuli and purported that "each individual ego is endowed from the beginning with its own peculiar dispositions and tendencies" (p. 226). Bergman and Escalona (1949) discuss unusualiy sensitive children as having "thin" protective barriers; Tennes (1972) refers to a "stimulus barrier." Escalona and Heider (1959) refer to variations in "sensory responsiveness," while Korner (1973) states "that the most enduring characteristics of an individual derive from his capacity to take in and synthesize sensory stimuli (Westman, 1973, p. 77). Albert, Neubauer and Weil (1956) speak of "unusual variations in drive endowment," and Murphy and Moriarty (1976) speak of a "drive to integration:" Honzik (1967) concluded from the Berkeley Guidance Study that children express the propensity to be primarily "reactive-expressive," or "reactive-inhibitive" even through adolescence. Thomas, et al. $(1963,1968,1977)$ have conducted considerable research in this area, and refer to the concept of temperament. They describe temperament as "a phenomenologic term used to describe the characteristic tempo, rhythmicity, adaptability, energy expenditure, mood, and focus of attention of a child, independently of the content of any specific behavior" (Thomas, 1968, p. 4) 
Research Studies

The New York Longi tudinal Study conducted by Thomas, Chess, Birch and Herzog $(1963,1968,1977)$ has added immeasureably to our understanding of constitutional individuality and, in particular, temperament. The con-.cept of temperament has been prevalent for many years and was defined in 1937 as:

Temperanent refers to the characteristic phenomena of an individual's emotional nature, including his susceptibility to emotional stimulation, his customary strength and speed of response, the quality of his prevailing mood, and all peculiarities of fluctuation and intensity in mood; these. phenomena being regarded as dependent upon constitutional make-up, and thereforc largely hereditary in origin. (Allport, 1937, p. 54)

The New York Longitudinal Study defined temperament as:

Temperament may best be viewed as a general term referrinc to the how of behavior. It differs from ability, which is con. cerned with the what and how well of behaving, and from motivation, which seeks to account for why a person does what he is doing. When we refer to temperament, we are concerned with the way in which an individual behaves. (Thomas, et al., 1968, p. 4)

The initial focus of Thomas, et al.'s study (1963) was to explore how characteristic behaviors or patterns of reactivity could be identified, and to assess how stable these patterns were during a child's first two years of life. The exploration developed into a longitudinal study by 1956 with increasing focus being the exploration of the "degree to which these characteristics are persistent and influence the development of later psychological disturbances" (p. I). A basic conviction of the research program, and stated as such, was that "temperamental characteristics of the infant made a fundamental contribution to the development of psychological individuality" (p. ix). The study also pondered the "contribution of the child's own characteristics of reactivity to the child-environment interaction," and questioned how the "direction of development might be considerably influenced 
by the nature of the child as an organism" (Thomas, et al., 1963, p. v.).

Nine categories of temperamental characteristics were differentiated by the study (Thomas, et al., 1963, p. v.):

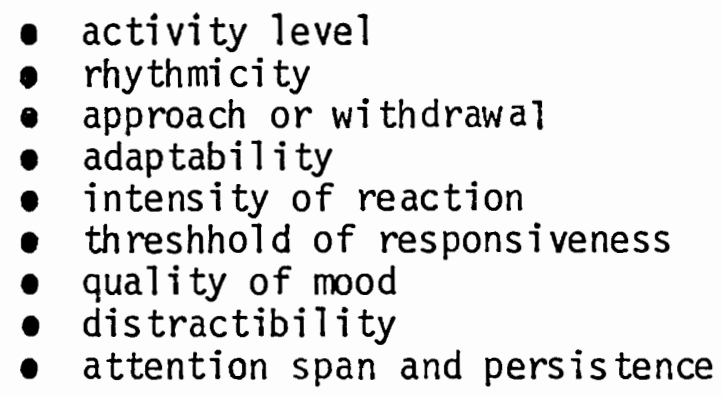

Graham, et al. (1973) studied 60 children ages 3 to 7 years who had one mentaliy $i 11$ parent, in order to test the applicability of Thomas, at a1.'s findings on a different population of children. Graham, et al. con- cluded that the study replicated aspects of Thomas, et al.'s findings: certain temperamental characteristics were identifiable and some were predictive of later psychiatric disorder. It should be noted that Graham, et a1. added an additional temperamental characteristics--fastidiousness.

Graham, et al. also confirmed Thomas, et al.'s contention of the interplay of the child to the environment. It was asserted, "The results of the present study suggest there is a link between adverse temperament and adverse family attitudes, and, possibly, relationships" (Graham, et al., 1973, p. 338).

A few additional studies are presented that confirm the constitutional individuality hypothesis, in particular: Fries and Woolf (197.1); Escalona and Leitch (1952); Heider (1966); and Murphy and Moriarty (1976).

Fries and Woolf (1971) studied the reaction of infants to a Startle Test and an Oral Test, and were able to categorize infants into five congenital activity types: three normal (active, moderate, and quiet), and two considered pathological (hyper/hypoactivity). Congenital activity type 
refers to the amount of activity a newborn infant expresses to stimuli. Anthony (1974) sumnarizes Fries and Wool f's hypothesis:

These early activity patterns were viewed as biological forerunners of the latter reactions to difficul ties predisposing the child to certain defense and escape mechanisms, which in turn made him vulnerable to particular neuroses or symp tom formation. (p. 5)

Escalona and Leitch (1952) studied 128 heal thy infants to determine normal variations in infant functioning. By 1959, the focus of their research shifted to explore the persistence of traits that were identifiable in infancy. Differences in motor activity, particularly the charar.teristic level of activity, was the criterion measure. The researche:s concluded that $18(67 \%)$ of the 27 individual predictions of later activity level they had made were confirmed.

An important premise that surfaced from this research was the imrpact activity level had on how the infant experienced the environment. It was noted that children with high activity levels could experience mastery over their environment because they developed their cognitive skills and also enhanced their ability to cope by learning how to manipulate the environment.

Murphy and Moriarty (1976) continued studying the children from Escalona's study but focused on a smaller sample--31 children, when the children were from 2 to 5 years of age, and on a circumscribed area-children's ability to cope. The project was referred to as the Coping Study and will be discussed later.

Heider (1966) studied the children from the Coping Study, however, she focused on "degrees of susceptibility to stress and with precusors of this susceptibility, or vulnerability, as they were seen in speech and in motor behavior" ( $p .9)$. Heider perceived the degree of vulnerability in 
infants and young children arising from the child's "management process," that is, the "ways in which the child handled himself in the case of stress and to the environment" (Anthony, 1974, p. 5). Heider concluded that vulnerable children were "less robust, less energetic, less active, less in-, terested, less trustful and less likely to be a part of a good motherchild relationship" (Anthony, 1974, p. 5). A relationship between physique and level of vulnerability was noted.

Murphy and Moriarty (1976), as noted earlier, explored the coping process in 31 children. Their aim was to study "children's efforts to cupe with their own problems and to explore the relation of these efforts to aspects of temperament and resources for growth" ( $p$. $x i)$. It was concluded from their research that:

The child's primary adaptational style in infancy will be largely shaped by the sensitivity, activity level, and reactivity patterns, as these influence goals and persistence towards goals, affect range and intensity, and predispositions to anxiety. (p. 188)

A succinct description of four. of the study children will exemplify what was explored. One boy was described as ectomorphic (slender), with high activity and high sensory reactivity, difficult vegetative ${ }^{*}$ functioning and poor sleep habits. Another boy, was described as mesomorphic (robust), as having good vegetative function, and low reactivity to sensory stimuli. Another boy, was described as being favorably to moderately robust, as having good vegetative functioning, low activity and high capacity to delay. A girl considered to be quite fragil, had difficult vegetative functioning, moderate reactivity to sensory stimuli and low activity Tevel. (Murphy and Moriarty, 1976, pp. 100-101)

*Frequent references are made to vegetative functioning. Vegetative functioning is defined as: "4 : affecting, arising from, or relating to involuntary bodily function" (Websters New Collegiate Dictionary, 1977, p. 1296) 
Murphy and Moriarty (1976) concluded that a child's capacity to maintain a sense of well being, a good physique and good vegetative functioning, high drive and a high level of functional stability were all characteristics that would promote "optimal development."

It was discerned that four groups of factors influenced the adaptational style of the children:

(1) The equipment and functioning of the organism (including strengths and vulnerabilities); (2) the psychological climate, demands, stimulation, stress, and growth--supportive factors in the environment and the ways in which. these are experienced; (3) the way the child uses his resources in dealing with the environment and his needs; and (4) the effects of these coping efforts. (Murphy and Moriarty, 1976, p. 155)

Murphy (1962, pp. 340-341) summarized how temperamental patterns or "models of styles" could interact with the environment to produce an individual style of coping. It was determined that clusters of temperamental patterns interacted in such a way to predispose a child to vulnerability or resiliency. Children with low sensory sensitivity, low autonomic reactivity, low drive, and good developmental balance would hạve an easy and natural adaptation because of the ease at which they could be gratified and could control themselves. Children who were overly-sensitive, had high drive and high autonomic reactivity with good developrental balaric: seemed to have flexible and adaptive resources which helped them to solve problems. These children would be more likely to encounter conflicts, however, because of their activity.

Children who were predisposed to more difficulties expressed the following patterns: 1) overly-sensitive, high drive and developmental imbalance; 2) overly-sensitive coupled with high autonomic reactivity, high drive and definite developmental imbalances.

Murphy and Moriarty (1976) inferred that children could sublimate 
difficult temperamental patterns in such a way that they became growth producing for the child and adaptive to his or her environment. A child's stubbornness might develop into a tenaciousness that facilitated an ability to overcome difficulties. Murphy and. Moriarty. (1976) reinarked that they were surprised at

The correlation between the children's infant capacity to terminate, protest, resist unwanted food or other stimuli and their preschool ability to structure new situations, fend off pressure, and in other ways act decisively in their dealings. (pp. 343-344)

The behaviors expressed in infancy corresponded with behaviors and characteristics displayed in preschool of

Stubbornness (maintaining. a stand despite the consequences): drive for mastery (struggle capacity, determination); ability to restructure the environment to create new patterns as well as to organize and provide one's own structure. (p. 136)

Temperament and VuTnerability

There seems to be consistency in the research findings regarding temperamental traits or cluster of traits that predispose a child to difficulties, vulnerabilities and behavioral problems. Thomas, et al. (1968) identified the following temperamental traits and constellations with behavioral disorders:

1) A combination of irregularity, nonadaptability, withdrawal responses, and predominantly negative mood of high intensity; 2) a combination of withdrawal and negative responses of low intensity to new situations, followed by slow adaptability; 3) excessive persistences; 4) excessive distractibility; and 5) markedly high or low activity level. (p. 71)

Langmeier (1975) studied 160 children at 3 years of age and younger who were in baby and toddler institutions in Czechoslovakia. It was noted that two extreme types of children were difficult: the strikingly inhibited or the strikingly restless, irritable, and hyperactive children. 
Graham, et al. (1973) state that problem children exhibit low habit regularity. Talbot and Howell (1971) determined that extremes in activity, apatheticness or excitability, a withdrawing or slow adaptation in approaching the environment, and distractibility, were behavioral traits and problematic characteristics associated with temperament. Murphy (1962) asserted that overiy-sensitive children with high autonomic reactivity and high drive coupled with developmental imbalances would have difficulties. Heider (1966) noted that "high sensory reactivity coupled with high drive or external cathexis, seemed important for level of vulnerabilit," (p. 82). She stated that children who exhibited activity levels at either extreme and who also had difficulty with their vegetative functioning (digestion, elimination and susceptibility to disease) would be more vulnerable.

Constitutional Individuality and Physique

Research exploring the relationship between temperament and physique, physiognomy, has been an area of interest for many years. Kretschmer (1925). studied physiognomy in order to determine if predispositions to psychosis were expressed in certain physiques. Kretschmer's work was influential in stimulating research in this area. Sheldon (1940, 1942) added credibility. to Kretschmer's research by developing a method of assessing and defining the relationship between physique and character. Sheldon (1940) distinguished three components of body build, or somatotypes: endomorphy, mesomorphy and ectomorphy, and later (1942) acknowledged that three main components of temperament or clusters of temperamental traits seemed to correspond with the somatotypes. Tyler (1965, pp. 439-400) charted the relationship as follows: 
Physique

Endomorphy--predominance of soft roundness in the body

Mesomorphy--predominance of muscle, bone, and connective tissue

Endomorphy--predominance of linearity and fragility
Temperament

Viscerotonia--predominance of relaxation and friendly, pleasure-loving traits

Somatonia--predominance of $\mathrm{vi-}$ gorous physical activity, adventurousness and dominance

Cerebrotonia--predominance of intellectual, introverted trends

The Viscertonia type of individual is charterized as having a slow tempo, placid, needing social contacts and approval, and loving physical comforts. Somatonia is characterized by a high energy level, assertiveness and competiveness. Cerebrotonia is characerized by inhibitiveness and restraint, needing privacy, apprehensiveness and shyness.

Sheldon (1942) found a correlation of +.83 between cerebrotonia and ectomorphy, +.79 between viscerotonia and endomorphy, and +.82 be tween somatonia and mesomorphy. Sheldon (1942) asserts, "Correlations of the order of .80 between the two levers of personality (morphology and temperament) indicate that temperament may be more closely related to the physical constitution than has usually been supposed" (p. 11).

Walker (1962) in research conducted at the Gesell Institute at Yale, correlated the body build of 125 nursery school children ages 2, 3 and 4, with how their teachers rated their behavior. Walker concluded that an association between physique and behavioral characteristics did indeed exist similar to that assessed by Sheidon. Walker found a positive correlation with behavior especially with ectomorphic children who he ascertained to be sensitive, irritable, nervous, shy, anxious and generally rated to be problem children. He also noted a significant correlation with mesomorphy as that noted by Sheldon. 
Constitutional Individuality and Autonomic Balance

Another area of investigation supporting the constitutional individuality hypothesis has been research on autonomic balance. Murphy and Moriarty (1976) have made numerous references to autonomic reactivity in their research. Considerable research has been conducted investigating the autonomic nervous system, particularly in infants, and has been reported in the literature (Lipton, et al., 1965).

Eppinger and Hess (1915) studied the autonomic nervous system and discovered a tendency toward dominance of the sympathetic or parasympathetic innervation. the "first group being predisposed to anxiety and the second being resistant to it" (Diamond, 1957, p. 133). Important to an understanding of how the autonomic nervous system relates to temperais is an awareness that individuals with parasympathetic innervation have regular digestive functioning and heal thy life-sustaining processes. The sympathetic predominant individual is hypothesized to subordinate these functions and processes to others "concerned with mobilizing resources for aggression and defense (Diamond, 1957, p. 132).

Wenger has extensively researched this area. He states that the autonomic nervous system "bears a significant relationship to certain. forms of personal-social behavior; more particularly, behavior that is associated with affective experiences" (Wenger, 1947, p. 301).

Wenger (1947) compared 10 children expressing sympathetic dominance with 10 expressing parasympathetic dominance. A relationship between body build, temperament and vegetative functioning was discovered, as well as psychological differences in the two groups of children. Wenger s tated that,

Children with autonomic scores indicative of functional parasympathetic predominance... manifest more emotional 
inhibition, less emotional excitability, and a lower

frequency of activity with less fatigue; and proved

to be more patient and neat than those chiTdren with

autonomic scores indicative of functional predomin-

ance of the sympathetic sys tem. (Wenger, 1947, p. 309)

Summation

The area of constitutional individuality is a complex subject warranting further research in the area of susceptibility to stress and to coping abilities--vulnerability and resilence. The subject has been extensively researched in terms of detecting individual differences and substantiating the constitutional individuality theory, but the relationship to vulnerability and resiliency and the impact of the enviru!lment is still in need of further investigation.

\section{CHILD-ENVIRONMENTAL INTERPLAY}

The child-environmental interplay has been referred to by Thomas, Graham, Murphy and Moriarty, and Kadushin, and seems essential to an understanding of constitutional individuality and $i$ ts contribution to what the environment has to offer. Thomas, et al. $(1963,1968,1977)$ strongly support an interactional interpretation of child development and refer to the concept of "goodness of fit" coined by Henderson (1913):

This concept implies that the adequacy of an organism's functioning is dependent upon the degree to which the properties of its environment are in accord with the organism's own characteristics and style of behaving. According to this view, optimal development in a progressive manner derives from the interaction of the individual with environmental opportunities and demands, that are consonant with his capacities and behavioral style. Conversely, disorders of functioning may be viewed as deriving in the first place from dissonances or discrepancies between the respective characteristics of the individual and his environment. (Thomas, et al., 1968, p. 137) 
A few studies that add credence to the significance of the childenvironmental interplay have been conducted by Chess (1963) and Carey, et. al (1974).

Stella Chess (1963) concentrated on 29 of the New York Longitudinal Study sample children who exhibited behavioral disturbances. She concluded that:

In the analysis of the specific case histories of the children who have come to psychiatric notice it is apparent that temperament alone does not produce behavioral disturbance...Rather, it appears that behavioral disturbance, as well as behavioral normality is the result of the interaction of temperament and significant features of his developmental environment. ( $p .147$ )

Carey, et al. (1974) studied 59 adopted infants and categorized them into difficult, intermediate high; intermediate low and easy children. There were 7 (11.9\%) difficult; 6 (10.2\%) intermediate high: 10 (2.6\%) intermediate low; and $30(50.8 \%)$ classified as easy children. These adopted infants were compared with 200 non-adopted infants. No significant differences in the frequency of difficult temperaments were found to exist in the adopted infants. Carey, et al. concluded that:

If adopted children can be shown conclusively to display a higher rate of behavior disorders, it cannot definitively be attributed to an excess of problems in their temperaments, or primary reactive patterns. Psychological factors in the adoptive family setting... would be a more likely explanation. (p. 357)

Escalona (1973) and Thomas, et al. (1968) contend that whether temperament persists over time can be determined by the impact of the environment. Escalona remarks that "certain individual characteristics may be maintained if subsequent experience supports and strengthens them" (p. 157). Thomas, et a1. (1968) state that temperament "is not immutable--can undergo a developmental course that is affected by environmental circumstances" (p. 4). Murphy and Moriarty (1976, p. 189) report cases where children exhibited extreme patterns of behavior, yet these behaviors normalized 
when the children were provided with a stable and consis tent environment.

Some children seem to have an ability to innoculate themselves in traunatic situations; this mechanism is in need of further research and as yet is not understood. Anthony (1974) alludes to this innoculation mechanism and how it develops from interactions with the environment.

It therefore seems that whereas risk is a function of the actual physical and psychological environment, vulnerability and invulnerability are states of mind induced in the child by exposure to these risks, and mastery is a force generated in the individual that leads him to test his strength constantly against that of the environment, and to assert himself even against overwhelming odds. ( $p .5)$

Anthony (1974) adds that "there is no doubt that both heredity and environmental factors work together, in differing proportions under different circumstances to decide the ultimate vulnerability of the individual" (p. 5$)$.

It seems that a child's vulnerability can be rectified by the environment. However, an increase in vulnerability will occur if interactions between the child and the environment result in added and continual deprivations.

Kadushin (1970) states that:

In the balance between what the child brings and what the environment has to offer, we have developed the conviction that what the environment offers, or fails to offer, is by far the major de terminant of developmental outcome, and that early environment is of crucial importance. Yet the outcome for the very deprived children in this study and the outcome for similar groups of children...suggest giving greater consideration to what: the child brings to the environment and greater weight to the influence for change of a later, healthier environment. (p. 219)

It is important that Kadushin's statement about the effect of a "later, heal thier environment" be kept in mind.

Pringle and Bossive (1960) studied 188 children who lived in children's institutions. Of the 188 children, 30\% were assessed to be stable and well adjusted. An intensive study was conducted on two groups of children from this main group of 188 children--the notably "stable" and the "severely 
maladjusted." A sample of 16 children (11 maladjusted and 5 stable) were distinguished. These children had been placed in institutional care before the age of 5 , had experienced continued separation from their biological parents for more than half of the ir lifetime, and were jadged to be notabiy "stable" or "severely maladjusted" by the criterion set.

Pringle and Bossive's (1960) conclusions elucidate Kadushins's statment about the need for a healthier environment to act as a palliative.

Our evidence suggests that the child who is rejected and remains unwanted is likely to become insecure, maladjusted and educationally backward.... Susceptibility to maladjustment and resilience to the shock of separation and deprivation appear to be determined by the quality of the human relationships avialbe to the child. (p. 4)

\section{CONCLUSIONS}

Continual research in the area of constitutional individuality and how it may mediate a child's capacity to successfully adjust to the circumsitances of his life is warranted. One child's trauma is a mere inconvenience to another. How much of this is determined by the child's temperament and how much to the environment is left unanswered. Factors that seem significant in impacting a child who experiences deprivation, separation or trauma, need to be considered in light of the duration of the experience, the age of the individual when it occurred, constitutional vulnerabilities and constitutional resilience, the aspects of the child's personality affected and the ameliorative effects of the environment. Clarke, et àl. (196) asked themselves, "What then, are the factors determining differences in vulnerabilities?" They suggest, and it seems substantiated by research and in the literature, that possibly it is : 
Inherited predispositions, experiences preceding and circumstances surrounding the deprivation, and the child's personality, in toto, in addition to the deprivation itself. (p. 33) 
Addis, R.S.; Salzberger, F., \& Rabl, E. A survey based on adoption case records. London: National Association for Mental Health, 1954.

Albert, A., Neubauer, P.B., \& Weil, A.P. "Unusual variations in drive endowment." In R.S. Eissler, A. Freud, H. Hartmann \& E. Kris (Eds.), The Psychoanalytic Study of the Child. New York: 'International Universities Press, Inc., 1956, XI, 125-163.

Aldrich, C.A., Sung, C., \& Knop, C. "The crying of newly born babies: I. community phase." Journal of Pediatrics, 1945, 26, 313-326.

Allport, G.W. Personality: a psychological interpretation. New York: Holt, $193 \overline{7 .}$

Anthony, E.J. \& Koupernik, C. (Eds.). The child in his family: children at psychiatric risk. New York: John Wiley and Sons, 1974.

Balint, M. "Individual differences of behavior in early infancy, and an objective method of recording them." Journal of Genetic Psychology, $1948, \underline{73}, 57-117$.

Bergman, P. \& Escalona, S. "Unusual sensitivities in very young children," In P. Greenacre, et al. (Eds.), The Psychoanalytic Study of the Child. New York: International Universities Press, Inc., 1949, III/IV, 333-352.

Birns, B. "Individual differences in human neonates' responses to stimulation." Child Development, 1965, 36 (1), 251-256.

Bohman, B. "A comparative study of adopted children, foster children and children in their biological environment born after undesired pregnacies." Acta Paediatrica, Scandinavia: Supple: 221, 1971.

Borgatta, E.F. \& Fanshel, D. Behavioral characteristics of children known to psychiatric outpatient clinics. New York: Child Welfare League of America, Inc., 1954.

Carey, W.B., Lipton, W.L., \& Myers, R.A. "Temperament in adopted and foster babies." Child Welfare, 1974, 53 (6), 352-359.

Chess, S. "Temperament in the normal infant." In J.C. Westman (Ed.), Individual differences in children. New York: John Wiley \& Sons, 1973, pp. 83-103.

Clarke, A.D.B. \& Clarke, A.M. "Some recent advances in the study of early deprivation." Journal of Child Psychology \& Psychiatry, 1960, 1, $26-36$. 
Diamond, S. Personality and temperament. New York: Harper \& Brothers, Publ ishers, 1957

Eppinger, H. \& Hess, L. "Vagotonia," Nervous Mental Disorders Monograph, No. 20,1915 .

Escalona, S.K. "The differential impact of environmental conditions as a function of different reaction patterns in infancy." In J.C. Westman. (Ed.), Individual differences in children. New York: John Wi ley \& Sons, 1973, 145-157.

Escalona, S. \& Heider, G.M. Prediction and outcome. New York: Basic Books, Inc., 1959.

Escalona, S. \& Leitch, M. "Early phases of personality development: a non-normative study of infant behavior." Monographs of the Society for Research in Child Development, 1952, 17 (I), I-7I.

Fries, Ri.E. \& woult, $P: J$. "Some hypolileses on tila role of the congenital activity. iype in parsonalicy devalopment," In R. Eissler, at al. (Eds.) The Psychoarialytic Study of the Cilili. New York: Iniarrational Universities Press, 1953, VIII, 48-62.

Fries, M.E. \& Woolf, P.J. "The influence of constitutional complex on: developmental. phases." In J.B. McDevi.tt \& C.F. Settlage (Eds.), Separation-individuation. New York: International Universitites Press, Inc., 197I.

Freud, S. Collected papers: Vol. II. London: Hogarth Press, Ltd., 1937.

Gesell, A. \& Ames, L.B. "Early evidences of individual ity in the human infant," Scientific Monthly, 1937, 45, 217-225.

Graham, P., Rutter, M., \& George, S. "Temperamental characteristics as predictors of behavior disorders in children," American Journal of Orthopsyciliatry, 1973,43 (3), 328-339.

Hartmann, H., Kris, E., \& Loewenstein, R.M. "Comments on the formation of psychic structure," In P. Greenacre, $\therefore$, et al. (Eds.), The Psychoanalytic Study of the Child. New York: International Universities Press, 1946, 11, 11-38.

Heider, G.M. "Vulnerability in infants and young children: a pilot study." Genetic Psychology Monographs,: 1966,- Z3; - 1-216.

Henderson, L.J. The fitness of the environment. New York: Macmillan Co., 1913.

Honzik, M. "Personality, consistency and change: some comments on papers by Bayley, Macfarlane, Moss, Kagan and Murphy." Vita Humana, 1967, 17, $139-142$.

Jaffee, B. \& Fanshel, 0. How they fared in adoption. New York: Columbia University Prêss, 1970 
Jones, H.E. "The galvanic skin reflex in infancy." Child Development, $1930,1,106-110$.

Kadushin, A. Adopting older children. New York: Columbia University Press, 1970.

Korner, A.F. "Individual differences at birth: Implications for early experience and later development." In J.C. Westman (Ed.), Individual differences in children. New York:- John Wiley \& Sons, 1973.

Kretschner, E: Physique and character. New York: Cooper Square Publishers, 1925 .

Lahti, J., Green, K., Emlen, A., Zadny, J., Clarkson, Q., Kuehnel, M. \& Casciato, J. Follow-up study of the Oregon project."Freeing children for permanent placement." Portland, Ore: Regional Research Institute for Human Services, Portland State University, 1978 .

Langmeier, J. \& Matejcek. Psychological deprivation in childhood. New York: John Wiley \& Sons, 1975.

Lipton, E.L., Steinschneider, A., \& Richmond, J.B. "The autonomic nervous sys tem in early life." New England Journal of Medicine, $1965,278,147-154$.

Maas, $H$. "Children in long-term foster care." Child Welfare, 1969, 39 $(6), 321-333$.

Meier, E.G. "Current circumstances of former foster children," Child Wel fare, 1965,44 (44), 196-206.

Murphy, L.B. \& Moriarty, A.E. Vulnepability, coping and growth. New Maven and London: Yale University Press, 1976.

Pringle, M.L.P. and Bossive, V.F. "Early, prolonged separation and emotional maladjustment." Journal of Child Psychology and Psychiatry, $1960,1,37-48$.

Raleigh, B. "Adoption as a factor in child guidance." Smith College Studies in Social Work, $1954,25,53-71$.

Ribble, M. "Infantile experience in relation to personality development." In J. McV.Hunt (Ed.), Personality and the behavior disorders.. New York: Ronald., 1944, 621-651.

Roe, A. \& Burks, B. "Adult adjustment of foster children of alochol ic and psychotic parentage and the influence of the foster home." Memoirs of the Section on Alcohol Studies, No. 3. New Haven: Yale University Press, 1945, 382-383. 
Seglow, J., Pringle, M.K. \& Wedge, P. Growing up adopted. England and Wales: National Foundation for Educational Research, 1972.

Sheldon, W.H. The varieties of human physique: an introduction to cons titutional psycno Togy. New York: Harper, 1940 .

Sheldon, W.H. The varieties of temperament. New York and London: Harper and Brothers Publishers, 1942 .

Shirley, M. The first two years, Vol. I. Postural and locomotor development. Minneapolis: University of Minnesota Press, 1931.

Skodak, M. \& Skeels, H.M. "A follow-up study of children in adoptive homes. Journal of Genetic Psychology, 1945, $\underline{66}, 21-58$.

Spitz, R. with Wolf, R. "The smiling response." Journal of Genetic Psychology Monographs, 1946, 34, 57-125.

Talbot, N.B., Kagan, J. \& Eisenberg, L. Behavioral Science in pediairic medicine. Philadelphia: W.B. Saunders Company, 1971, 1-89.

Tennes, K.H. "The stimulus barrier in early infance: an exploration of some formulations by John Bergman." Psychoanalysis and Contenturary Science, 1972, 1, 206-234.

Thomas, A., Chess, S., Birch, H.G., Hertzig, M. \& Korn, S. Behavioral individuality in early childhood. New York: New York University Press, 1963.

Thomas, A., Chess, S., Birch, H.G. Temperament and behavior disorders in children. New York: New York University Press, 1968.

Thomas, A. \& Chess, S. Temperament and development. New York: Brunner/ Mazel, Publishers, 1971.

Thomas, C.B. "The resolution of object loss following foster nome placement." Smith College Studies in Social Work, 1967, 37, 371-385.

Tizard, B. \& Rees, J. "A comparison of the effects of adoptions, restoration to the natural mother, and continued institutionalization on the cognitive development of four-year-old children." Child Development, $1974, \underline{45}(1), 92-99$.

Tyler, L. The psychology of human differences.. New York: AppletonCentury-Crofts, 1965.

Van Thesis, S. How foster children turn out. New York: State Charities Aid Association. 1924.

Walker, R.N. "Body build and behavior in young children." Monographs of the Society for Research in Child Development, 1962, 27 (3), 1-94, Serial \#84. 
Washburn, R.W. "A study of smiling and laughing of infants in the first year of life." Genetic Psychology Monographs, 1929, 6 , 397-539.

Wenger, M.A. "Preliminary study of the significance of measure of autonomic balance." Psychosomatic Medicine, 1947, 9. 301309 . 


\title{
CHAPTER III
}

\author{
METHOD
}

\section{Purpose}

In 1976 the Regional Research Institute for Human Services at Portland State University conducted a follow-up study of foster children who were part of the demonstration project, "Freeing Children for Permanent Placement" initiated by Children's Services Division. Permanent placements were diligently sought for 509 children in Oregon between November 3, 1973 and 0ctober 31, 1976. The purpose of the follow-up study, which began in November 1976, was to determine the stability and success of the placements. (Lahti, et al., 1978).

A sub-study of the follow-up study was initiated which utilized data collected by the follow-up study. The data included pre-placement caseworker ratings of how placeable a child was for a permanent home, parent interviews and parent questionnaires, and interviews with the children which included a child's self-report (Self-Concept Inventory). Socioeconomic information on the placement parents was also available. All of the data were available for 89 of the 160 children in the follow-up study, thus forming the population for the sub-study.

The sub-study endeavored to distinguish two groups of children that had unusual results: 1) those children whose characteristics or condition was rated as favorable for permanent placement, yet whose adjustment to placement at follow-up was poor; and 2) those children rated as hard to place because of their characteristics of condition, yet who adjusted we11 
to their respective placements.

Caseworkers had rated the children on whether conditions existed that might prevent placing the child in a permanent home. The workers were asked to rate the child in three areas: the child's physical condi-* tion, the ability of the child to cope socially, and any financial outlay that might be necessitated due to physical or behavioral conditions of the child. The workers also gave an overall rating which represented a global assessment of the child's placeability. (See Appendix A: Placeability Barriers). The follow-up study. (Lahti, et al., 1978) referred to the characteristics or condition of the child that might impose difficulties in placing the child as "placeability barriers."

Theorists hypothesize that children who are not robust, who have poor vegetative functioning and exhibit unusually high or low activity, will have more difficulty adjusting and thus be more vulnerable. Given this, those children given either high or low ratings on their physical condition, coping characteristics and on their overall characteristics or condition were selected as children that might reflect either vulnerability or resiliency.

Since there was no direct way of identifying vulnerable or resilient children independently of the adjustment they had made to placement, the post-placement* adjustment scores given the children by the follow-up project distinguished the children as having either good or poor adjustment. The child's post-placement adjustment was assessed from the data collected; seven factors*t emerged from the data and an overall measure of adjustment

\footnotetext{
*Post-placement means at the time of the follow-up interview

**For the results of the factor analysis, see Lahti, et al., 1978
} 
was determined. The seven factors are:

I) Parent is satisfied with a socially accepted child

II) Child has school problems

III) Child's health is good

IV) Secure placement with few problems

V) More authority would help

VI) Nuclear family adjustment is good

VII) Child is obedient

If a child scored above the mean on 5 or more of the seven factors, he or she was perceived as having good adjustment; those scoring above average on 4 of the seven factors had medium adjustment; and, those having above average on 3 or less of the seven factors were considered to have poor adjus tment.

\section{SAMPLE SELECTION}

The sample selected for the sub-study was also determined on this basis. Those children who scored 5 or more on the seven factors represented the good adjustment group; those scoring 3 or less on the seven factors represented the poor adjustment group; the medium group was excluded.

\section{TABLE II}

CLASSIFICATIOIN OF POST PLACEMENT ADJUSTMENT BASED ON NUMBBER OF FACTORS ON WHICH CHILD SCORED ABOVE THE MEAN

Post-Placement Adjus tment

Number of Factors Child Scored Above the Mean

\begin{tabular}{lccc}
\hline & $0-3$ & 4 & $5-7$ \\
\cline { 2 - 4 } Good & & 19 & 35 \\
\hline Medium & & & \\
\hline Poor & 35 & & \\
\hline
\end{tabular}


The children's post-placement adjustment scores were cross-tabulated with the ratings given by the caseworkers on how placeable the child was given the child's characteristics or condition. Those children who were rated as harder to place (high "placeability barriers"), yet adjusted well. to placement, and those children who should have had no difficulty (low "placeability barriers") accarding to the caseworker's rating, yet adjusted poorly to placement were selected. A sample of 28 children satisfied this criteria, approximately one-third of the 89 children.

\section{TABLE III}

POST-PLACEMENT ADJUSTMENT SCORES CROSS-TABULATED WITH

CASEWORKER PRE-PLACEMENT RATING QF: THE

CONDITION OF THE CHILD

Post-Placement Adjustment

Caseworker Pre-Placement Rating of the Condition of the Child

Low Risk*

High Risk

Poor Adjus tment

Did worse than

expected $n=9$

Good Adjustment

Did better than

expected $n=19$

*Risk of making a poor adjustment to placement

It is hypothesized that the children who had high "placeability barrier" yet good adjustment, represented the presumably resilient children $(n=19)$; those children who had low "placeability barriers" yet low adjustment at post-placement, represented the presumably vulnerable child$\operatorname{ren}(n=9)$. 


\section{I) Child's Self-Concept Inventory}

The children were asked to select individual pictures from a booklet that portrayed children engaged in various activities: playing with other children, fighting, doing school work: The child was asked to select the picture that was most like him or her from two or three choices, while an interviewer read a description of the picture. Nineteen questions were asked. The nineteen questions clustered to form nine factors (See Appendix $B$ for the nineteen. questions). The nine factors are:

I) Child who does his school work

II) Child who helps other children

III) Cheerful, gregarious child

IV) Happy child

V) Child who plays with other children

VI) Child who can apply himself and do motor tasks

VII) Happy child who plays. with other children

VIII) Child who pushes wagon while others ride

IX) Child who can play with others without fighting

The two groups of children were expected to respond differently to the Self-Concept Inventory, i.e., have different self-images.

The rationale for using the Child's Self-Concept Inventory was in part due to the findings of the follow-up study which noted that "The most important thing we learned was that positive child self-image was associated with high present status" (Lahti, et al., 1978, p. 4.21).

A. stepwise discriminant analys is was performed using ten of the nineteen questions expected to reveal differences. (See Appendix c: Stepwise Discriminant Analysis)

The ten responses were:

- Child plays with others rather than fighting with them

- Child is able to build a block house 
- Child socializing in group rather than being alone

- Child who has a happy disposition rather than a sad one

- Child who is able to put together a puzzle

- Child who pushes a wagon rather than rides

- Child who plays with other children rather than by himself

- Child who helps others up rather than being helped

- Child is able to do schooi work

- Child gives piggyback rides rather than receives them

\section{II) Parent Interview and Parent Questionnaire}

Data collected from the parents answered questions regarding the child's initial adjustment and health at the time the child was first placed. The questions are significant as they deal with how the child reacted when he or she first entered the home, the behavior and personality of the child, and the number of problems the child had. It was expected that the answers would reveal differences in the two groups of children of a constitutional nature which might have accounted for their adjus tment or Tack of adjustment.

The rationale for focusing on the initial status and health, aside from expecting the data would reveal differences in the two groups, was the significance these factors played in the final status of the overall sample of the follow-up study.

The child's adjustment when he first entered the home was significant to his present status,... We found that a child who had good family adjustment, who made friends easily, had fewer problems, and needed discipline less at first, tended to score high on present status. (Lahti, et al., 1978, p. 4.20)

Our results indicate that the child's health when he first entered his current home affects his present status. If he was heal thy at first then he was more likely to score in the medium or high status group. (Lahti, et al., 1978, p. 4.17). 
A stepwise discriminant analys is was performed using the Initial Status and Health Status variables to determine if these factors revealed any differences in the two groups of children.

\section{III) Validating Analysis}

A correlation matrix was also performed on the ten Child Self-Concept variables, the Initial Status and Health variables. (See Appendix D for variables used). The parents perception of the child's personality, behaviors, and health when the child was first placed were correlated with how the child perceived himself or herself at the time of the follow-up. It was hypothesized that if constitutional factors were important in postplacement adjustment and if the child's self-concept reflects constitutional factors, then why would health and initial status not be correlated with self-concept?

\section{IV) Environmental Variables}

The literature indicates that the interaction of the child to his or her environment is significant in mediating the child's capacity to adjust to $1 \mathrm{ife}$ circumstances. In order to ascertain what potential influence the environment may have had on the 28 children.'s adjustment, socio-economic information available on the placement parents, and the assessment of how permanent the placement was perceived to be by both parent and child, was analyzed representing the control variables.

Many of the children had moved up in socio-economic status when they were placed, which may have contributed to their adjustment. A t-test was performed on the socio-economic data to determine whether there was any differences in the socio-economic status of the two groups of children.

The follow-up study (Lahti, et al., 1978) had concluded that the sense 
of permanency that prevailed in the home was the most significant indicator of the placements success. A stepwise discriminant analysis was performed using the permanency variables (See Appendix E for variables used) to determine if the sense of permanency discriminated differences in the two groups of children.

SUMMARY

In summary, three kinds of data were used to discriminate between the presumably vulnerable and presumably resilient children: 1) the child's self-concept; 2). parent reports of child's initial adjustment and health; and 3) environmental factors represented by socio-economic status of the placement parents and the perceived sense of permanency in the home. The overall study hypothesis was that child variables, i.e., selfconcept, health and initial adjustment, would differentiate any differences between the two groups of children; while; socio-economic status and perceived permanency representing the environmental interplay, would not contribute to any differences. 
CHAPTER IV

\section{RESULTS}

An analysis of the child's self-concept variables revealed the most significant information of all the analyses performed on the data. A stepwise discriminant analysis was performed using the self-concept variables. Six of the ten variables successfully discriminated between the vulnerable and resilient groups, accounting for fifty-three percent of the variance'. The other data analyzed--Initial status, Health status, Permanency and Socio-economic status--did not reveal any significant differences between the two groups. Reported in detail in this chapter are the results of the analysis based on the child's self-concept. This analys is was theoretically the most important. (See Appendix F, G, H, I).

\section{Child's Self-Concept Analys is}

A stepwise discriminant analysis was performed using ten of the nineteen self-concept variables. These ten variables were expected to express significant differences between the two groups of children. The Means and Standard Deviations are presented in Table IV. 
Uf the ten variables, the stepwise discriminant analysis revealed that six of the variables contributed fifty-three percent to the difference between the two groups of children. This is illustrated in Table V. and Figure 1.

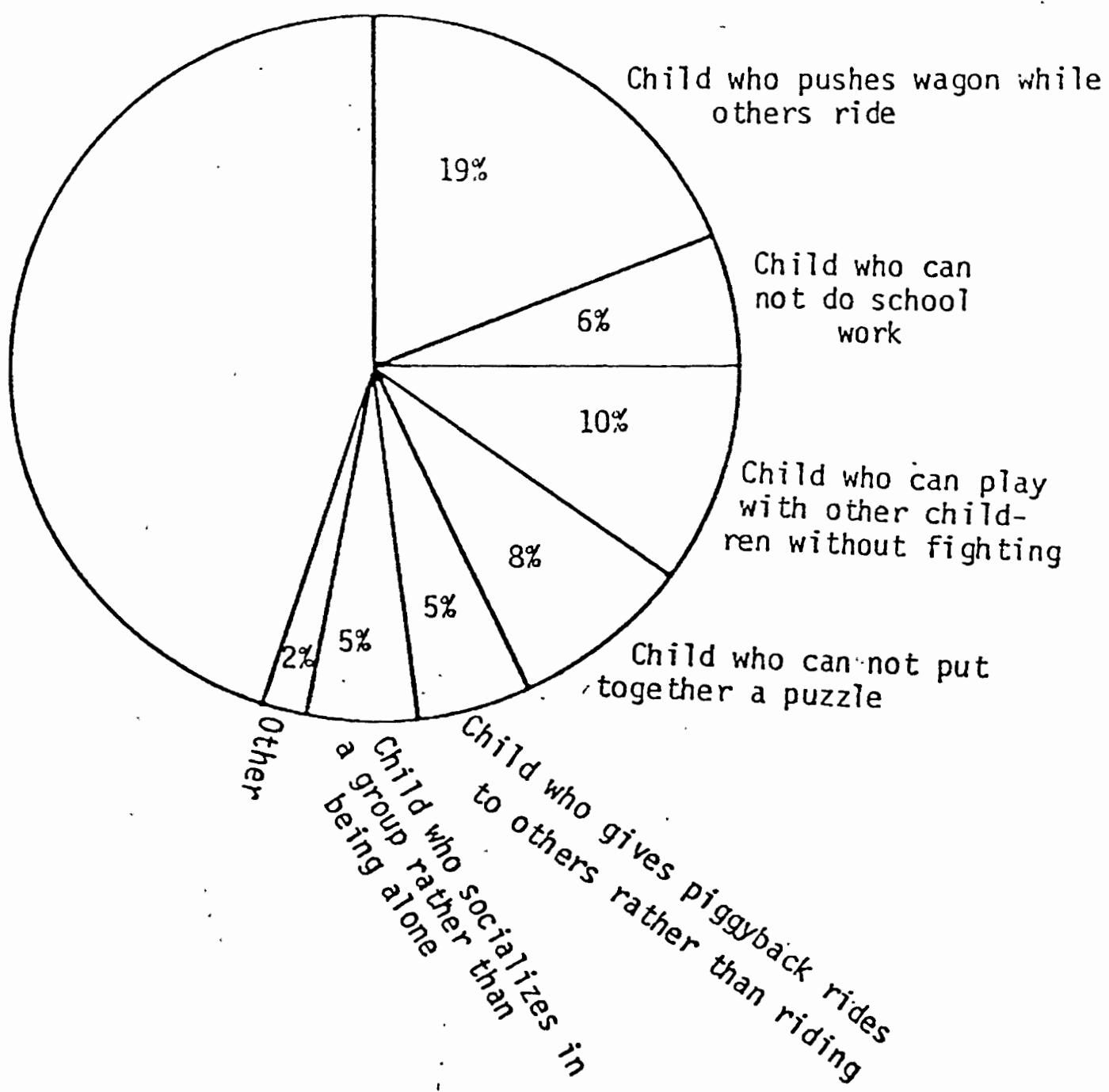

Figure 1. Variábility Accounted for by Discriminators on Child's SelfConcept Analysis: $53 \%$ 


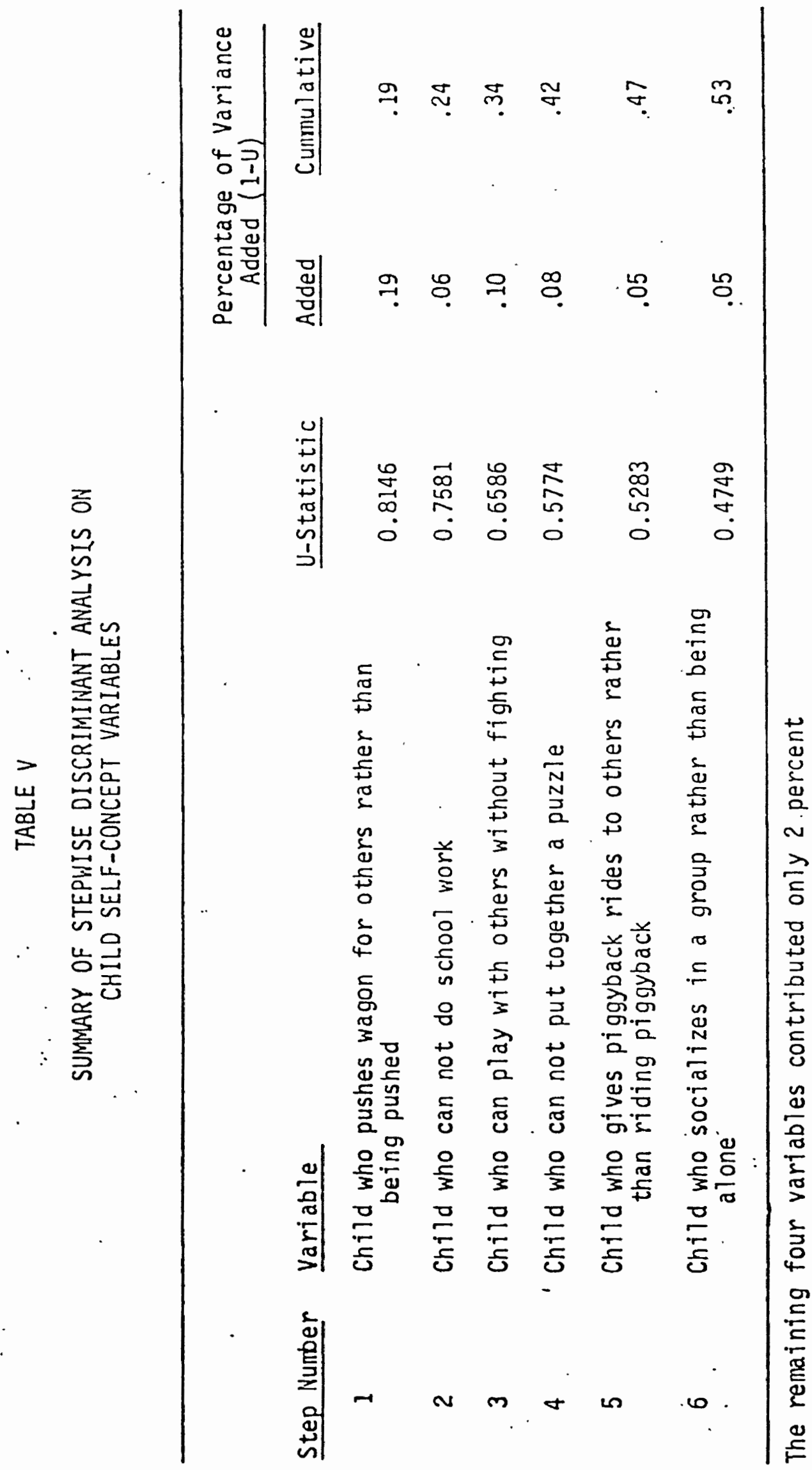


The child responses discriminating between the vulnerable and resilient groups are:

- Child who pushes wagon while others ride

- Child who can not do school work

- Child who can play with others without fighting

- Child who can not put together a puzzle

- Child who gives piggyback rides to others rather than riding

- Child who socializes in a group rather than being alone

Ninety-three percent of the cases were "correctly" classified according to the hypothes is as illustrated in Table VI.

\section{TABLE VI}

NUMBER OF CASES CLASSIFIED ACCORDING TO HYPOTHESIS

\begin{tabular}{lcc}
\hline GROUPS & Resilient $(n=19)$ & Vulnerable $(n=9)$ \\
\hline Resilient $(n=19)$ & 18 & 1 \\
\hline Vulnerable $(n=9)$ & 1 & 8 \\
\hline
\end{tabular}

Number correctly classified: $26 / 28=93$ percent

The presumably resilient child presents a picture of a child who perceives himself or herself in a helpful capacity as evidenced by pushing other children in a wagon and by giving piggyback rides to others. It can also be inferred that this child sees himself or herself as possibly stronger.and capable. The presumably resilient child also seems to perceived himself or herself as a child who socializes in a group rather than being alone and one who plays with other children rather than fighting with them. The two additional variables that contributed to the difference between the two 
groups of children are the presumably resilient child's inability to do school work or to put together a puzzle, which represent the child's inability to apply himself or herself and to do motor tasks--cognitive abilities.

The presumably vulnerable children expressed perceiving themsel ves as capable of applying themselves to school work and able to perform motor tasks. They also indicate being helped and thus seem more passive as evidenced by their taking rides in the wagon rather than pushing it, and also receiving piggyback rides rather than giving them. They also seem to see themselves as fighting more with other children rather than playing with them, and alone more than socializing in a group.

Validating Analys is

If resilience is important in post-placement adjustment and if the child's self-concept reflects that resilience, then why would heal th and initial status adjustment after placement not also be correlated with positive self-concept? Correlations were performed between the ten child selfconcept variables, and each of the initial status and heal th variables. (See Table VII and Appendix 0).

The initial status and health variables represented the parent's perception of the child when he or she first entered the home. The self-concept variables reflect how the child perceived himself or herself at the time of the follow-up study.

The presumably resilient children expressed significant correlations on five of the ten self-concept variables:

- Child socializing in a group rather than being alone

- Child has a happy disposition rather than a sad one

- Child can put together a puzzle 
- Child pushes wagon rather than rides

- Child plays with other children rather than being left out

These five variables correlated with parental ratings of the child's initial adjustment:

- Child had few problems

- Child's behavior in and outside the home was good

- Child got along with his or her brothers and sisters

- Family adjustment to the child was good

- Child was heal thy

TABLE VII HERE

In interpreting these correlations a pattern emerges. The presumably resilient child perceives himself or herself as socializing in a group rather than being alone, and is rated by the parents as having fewer problems, and as having good behavior in and outside the home when the child first came. The presumably resilient child perceives himself or herself as having a happy disposition rather than a sad one,.. and is rated by the parents as relating well to siblings in the home and the family's adjustment to the child being good. The child's ability to get along well with siblings is also correlated with the child's perception of himself or herself as capable of putting together a puzzle. The correlations with the health variables portray a healthy child who perceives himself or herself as pushing a wagon rather than riding in it. This particular child self-concept response (pushing the wagon) represents the child perceiving himself or herself as helpful 


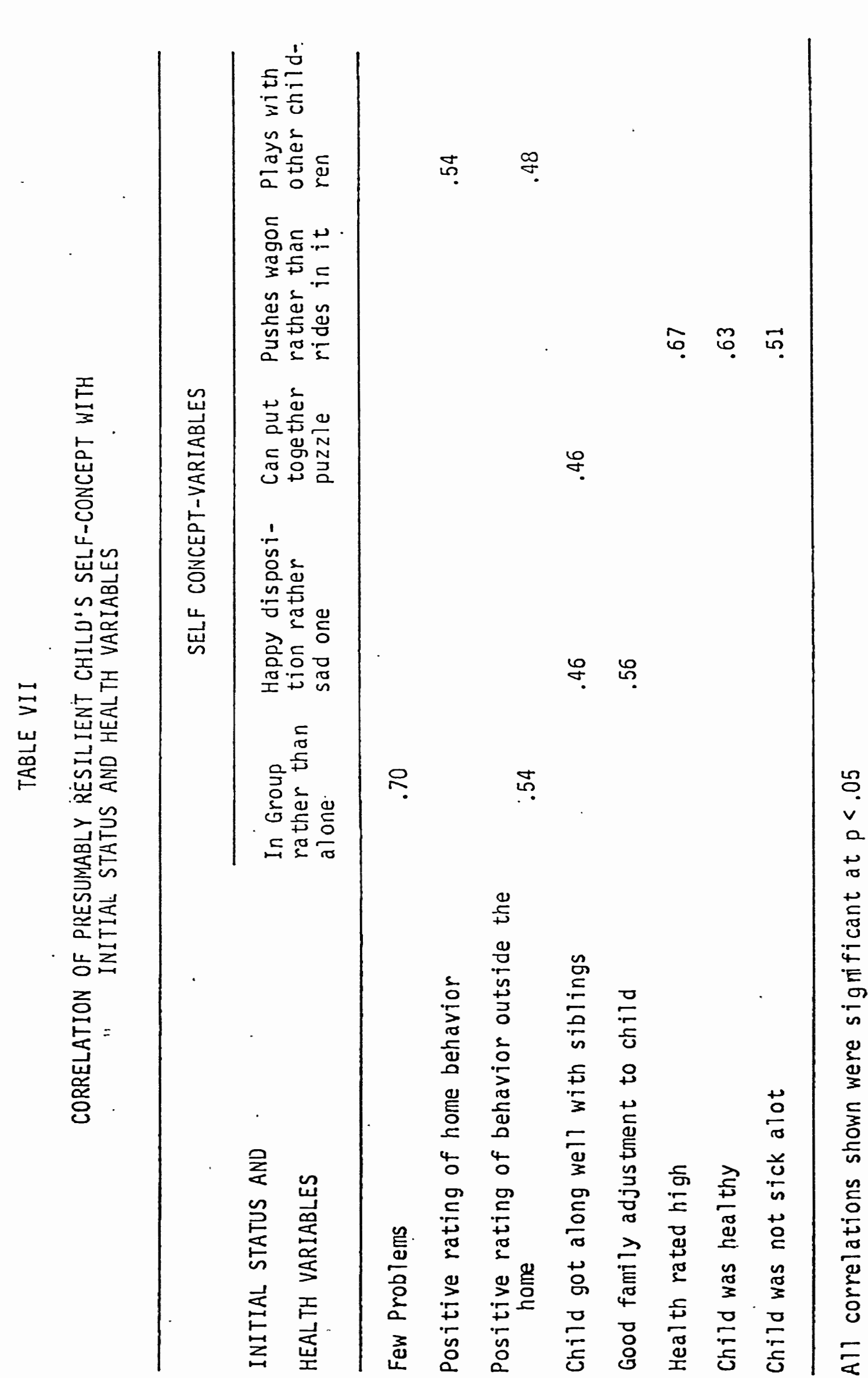


can be inferred to represent strength and capability, which seems substantiated by the correlations on the heal th variables.

It seems that the parents positive perception of the child when he or she first entered the home correlates with the child's subsequent perception of himself or herself as positive. This was also concluded by the follow-up study.

Fewer correlations existed between the child's self-concept variables and the initial status and health variables for the presumably vulnerable children. Only two of the self-concept variables proved significant correTates:

- Child can build a block house

- Child rides in wagon rather than pusines

These two child self-concept variables correlated with the parental-ratings of the child when he or she first entered the home:

- Child had few problems

- Adjustment to a new child was easy

\section{TABLE VIII}

CORRELATION OF PRESUMABLY VULINERABLE CHILD'S SELF-CONCEPT WITH INITIAL STATUS ANO HEALTH VARIABLES

INITIAL STATUS AND

HEALTH VARIABLES

SELF-CONCEPT VARIABLES

Can build block house: Rides in wagon

Few Problems

Adjustment to new child was easy

Improvement in home behavior 
Initial Status and Heal th Status Analys is

Nine variables were used for a stepwise discriminant analysis: six related to the child's initial adjustment (status), and three to the child's health when he or she first entered the home. The stepwise dis-. criminant analysis revealed no signficant differences between the two groups of children.

The Initial Status and Heal th Status variables used are:

Number of problems the child had

Behavior in the home (a)

Behavior outside the home (a)

Even from the beginning the child made friends easily (b)

At first the child did not seem to get along with siblings(b)

I had more discipline problems at first (b)

Health rating from $1=$ poor, to 10 = best

From the first this child has been health (b)

At first the child was sick alot (b).

Scale: (a) 1 = worse, 10 = best

(b) 1 = strongly disagree, to $4=$ strongly agree

The Mieans and Standard deviations of the stepwise discriminant analysis are presented in Appendix $F$ and $H$. A summary of the analys is is presented in Appendix G: and H.l.

Seventy-nine percent of the cases were "correctly" classified according to the Initial Status hypothesis as illustrated in Table IX.

TABLE IX

NUMBER OF CASES CLASSIFIED ACCORDING TO INITIAL STATUS HYPOTHESIS .

GROUPS

Resilient $(n=19) \quad$ Vulnerable $(n=9)$

\begin{tabular}{lcc} 
Resilient $(n=19)$ & 14 & 5 \\
\hline Vulnerable $(n=9)$ & 1 & 8
\end{tabular}

Number correctly classified: $22 / 28=79$ percent 
Sixty-eight percent of the cases were "correctly" classified according to the Heal th Status variables, as illustrated in Table $*$.

TABLE $X$

NUMBER OF CASES CLASSIFIED ACCORDING TO HEALTH STATUS HYPOTHESIS

GROUPS

Resilient $(n=19) \quad$ Vulnerable $(n=9)$

\begin{tabular}{lll} 
Resilient $(n=19)$ & 14 & 5 \\
\hline Vulnerable $(n=9)$ & 4 & 5
\end{tabular}

Number correctly classified: $19 / 28=68$ percent

Though the stepwise discriminant analysis discriminated no significant differences between the two groups of children, Tables IX and $X$, indicate a leaning towards affirmation of the hypotheses.

Environmental Variables Analysis

Because of the significance the environment can play in affecting one's life, two control variables representing the contribution of the environment were tested: socio-economic status of the placement parents, and the assessment of how permanent the placement was perceived to be by the parents and the children.

Socio-Economic Status. A t-test was performed to determine if the socio-economic status of the two groups of parents proved different. The t-test showed no significant differences, as was hypothesized.

Permanency. Four permanency variables were used for a stepwise discriminant analysis. The Means, Standard deviations and summary of 
the anaiysis are presented in Appendix I and I.1. The permanency variables showed no differences between the two groups of children as hypothesized.

The four permanency variables used are:

Parents understanding of the arrangement when the child first came (a)

Child's understanding of the present arrangement (a)

Parents understanding of the present arrangement (a)

The child is concerned about whether or not he or she witl have to move again (b)

Scale: (a) 1 = temporary, to $4=$ permanent

(b) 1 = strongiy disagree, to $4=$ strongly agree

Seventy-nine percent of the cases were "correctiy" classified according to the Permanency hypothesis as illustrated in Table XI.

TABLE XI

NUMBER OF CASES CLASSIFIED ACCORDING TO PERMANENCY HYPOTHESTIS

GROUPS

Resilient $(n=13)$

Vulnerable $(n=9)$

Resilient $(n=19)$

18

1

Vulnerable $(n=9)$

5

4

Number correctly classified: $22 / 28=79$ percent

\section{Summary}

The data analyses indicates that the child's self-concept, initial adjustment (status) and heal th reflect constitutional factors that confirm the vulnerability-resiliency hypothesis. The environmental variables did not contribute to any significant differences between the two groups of children which seems to give stronger weight to the impact of constitutional factors within the child for determining successful adjustment. 


\section{CHAPTER $V$}

\section{CONCLUSIONS}

The purpose of the study was to search for patterns and interpretable differences between two groups of children who expressed a "uniqueness" by virtue of contradicting the pre-placement caseworker rating of their placeability. It was hypothesized that this "uniqueness" would further reveal differences between the two groups of children of a constitutiona? nature.

With the data available on the children, it was not feasible to distinguish specific temperamental characteristics such as those delineated by Thomas, et al. It was not the purpose of this study to attempt this. It is possible, however, to make inferences about the temperament and constitution of the children from the responses the children made to the Self-Concept Inventory. As discussed in the Results Chapter, the self-concept data provided the most theoretically significant information.

The resilient children manifested characteristics expressive of sociableness and helpfulness. The variables related to perceived helpfulness, i.e., giving piggyback rides and pushing the wagon for others, can also be interpreted as expressing robustness, capability and perhaps being actively oriented. Interestingly, the resilient children perceive themselves neither as capable of doing school work nor applying themselves to motor tasks as the vulnerable children.

The vulnerable children perceive themselves as capable of doing school 
work and able to do motor tasks, yet also portray themselves as more alone and as fighting more with other children, thus not as social. In addition, the vuinerable children perceive themselves as the recipients of help and reflect more passive characteristics. It is possible that this passivity was due to a lack of robustness.

What is significant about the resilient child perceiving himself or herself as social and helpful, and not as cognitively adept? How does this contribute to adjustment? Studies on constitutional individuality have confirmed that a child contributes immensely to the interaction between himself or herself and to the environment, particulariy wi.th the parent. If the child is responsive to the parent, the parent is more likely to reciprucate However, if the child is difficult--crys easily and does not seem to enjoy physical contact, the parent may interprete this as rejection and react negatively to the child. The child in turn, is more likely to experience his or her social-interpersonal environment as negative. Perhaps the vulnerable children in the study experienced their social-interpersonal world negatively and retreated into themselves and to the congnitional world. Perhaps the resilient children were more responsive from birth, experienced positive recipriocity from this or her warld and chose to develop social skills and abilities rather than those more narrowly cognitive. This of course is purely conjecture.

The correlational analysis and the resilient child's'self-report seem to substantiate the hypotheșis that robustness (as expressed by good health and an active self-concept) was a factor in the child making a successful adjustment. The parent's rating of the child as healthy and the subsequent 
perception by the child of pushing a wagon rather than riding in it, is particularly suggestive as three of the four health variables correlated significantly with this one child's self-concept response. The follow-up study (Lahti, et a1., 1978) noted that if the parents rated the child as healthy and the child adjusted well when he or she first entered the home, the child fell into the high adjustment group at follow-up. This was also confirmed by the sub-study; when the parents perceived the child as adjusted and healthy, the child subsequently perceived himself or herself as social, helpful and robust. How much of the adjustment was due to factors within the child and how much to the parents perception and expectations that the child would indeed adjust, one can only surmise. Parental expectations and opinions are crucial for a child's developing self-image.

The stepwise discriminant analysis of the initial status and heàlth variables--the parental ratings of the child both behaviorally and physically when the child first entered the home, revealed no significant differences between the vuinerable and resilient children. Thus, it seems plausible that the condition of the child, as expressed by his or her selfconcept, actualiy mediated adjustment. If the parent's perceptions of the child were the determining influence mediating adjustment, it seems likely that differences between the two groups of children would have been discriminated. Since no differences were discriminated, the child's self-concept analysis is given even greater weight and adds support to the constitutional individuality hypothesis.

In concluding, the significant results are that, on the basis of the child's self-concept data, we were indeed able to distinguish between the two groups of children who had been identified as doing better or worse than 
expected, and the results were consistent with the vulnerability-resilence hypothesis. The resilient child expressed robustness, sociableness and helpfulness. The vulnerable child expressed competence with cognitive skills and abilities, but perceived himself or herself as more passive and unhelpful, and perhaps not as robust.

The two groups were defined in terms of doing better or worse than expected based on their subsequent adjustment, not on their initial adjustment to placement. Therefore, variation in subsequent adjustment was assured for the purposes of discrimination.

It seems that constitutional differences require time to assert themselves. Under the stress of initial placement, one would expect all children to experience difficulty, but given time in the home the child has a chance to settle down and fare well or not depending on the inner-resouces the child brings to that environment. Though for the most part, the children were placed in an "improved environment"--permanent placement--that did not ensure adjustment. This could be important for placement programs. It may take time for children to overcome situational change and for constitutional differences to surface in the form of improved social adjustment. The results also suggest that it may be wise to pay extra attention to children who supposedly will not do well in placement.

Life gives no guarantees to any child, anywhere, that life will be without trauma, wi thout limited or prolonged periods of separation from parents, wi thout hurts. The results speak, then, to all children, in all families, who at times face the possibility of some measure of deprivation. And the results suggest that a child's resiliency and capacity for adaptation very often enable him to struggle effectively and successfully with the tragic circumstances of life. Despite the inevitability of tragic circumstances, many children have emerged from such struggles reasonably hea7thy, reasonably happy, reasonably well-adjusted people. 


\section{BIBL IOGRAPHY}

\section{Additional Sources Consulted}

Ainsworth, M.D. "Object relations, dependency, and attachment: a theorectical review of the infant-mother relationship." Child Development, $1969,40,969-1025$.

Anthony, E.J. \& Koupernik, C. (Eds.) The child in his family. Vol. I. New York: John Wiley \& Sons, $19 \overline{70}$.

Bohman, M. Adopted children and their families: a follow-up study of adooted children. their backaround, environment and adjus tment. Stockholm: Proprueis, 1970 .

Bowiby, J. Separation anxiety: A critical review of the literature New York: Child Welfare League of America, 1962.

Casler, L. "Maternal deprivation: A critical review of the literature." Monographs of the Society for Research in Child Develooment, 1961, 26 (2).

Chess, S., Thomas, A., Rutter, M. \& Birch, H. "Interaction of temperament and environment in the production of behavioral disturbances in children." American Journal of Psychiatry. August, 1963, 120 (2) 142-148.

Chess, S. "Temperament and learning ability of school children." In $S$. Chess and A. Thomas (Eds.), Annual Proaress in Child Psychiatry and Child Development. iNew York: Bruner/Mazel Publishers, 1969, 125-136.

Chess, ,. S. "Temperament and children at risk." In E.J. Anthony and C. Koupernik (Eds.), The child in his family. New York: John Wiley. \& Sons, 1970 .

Clarke, A.M. \& Clarke, A.D.B.(Eds.) Early Experience: Myth and Evidence. New York: The Free Press, 1976.

Cohen, D. "Adoption." Psychology Today, November-1977, 11, 128-132.

Elonen, A.S., Schwartz, E.M. "A longitudinal study of emotional, social, and academic functioning of adopted children." Child Welfare, 1969, 48 (2), 72-78. 
Emlen, A. Overcoming barriers to planning for children in foster care. Washington, D.C.: Govemment Printing Office, 1978.

Emlen, A. Barriers to planning for children in foster care. Portland, Ore: Regional Research Institute for Human Services, Portland State University, 1976.

Fisher, R.A. "The use of multiple measurements in taxonomic problems.". - Anals of Eugenics, $1936, \underline{7}, 179$.

Greenacre, P. Trauma, growth, and personality. New York: W.W. Norton \& Company, Inc., 1952.

Jost, H. \& Sontag, L. "The genetic factor in autonomic nervous sys tem function." Esychosomatic Medicine, 1944, 6, 308-310.

Kadushin, A. "Reversibility of trauma. A follow-up study of childre:? adopted when older." Social Work, 1967,. 12 (4), 22-23.

Kirk, H.D., Jonassohn, K. \& Fish, A.D. "Are adoptee children especially vulnerable to stress?" Archives of General Psychiatry, 1966, 14 (3), 291-298.

Korner, A.F. "Individual differences at birth: implications for early experience and later development." American Journal of Orthopsychiatry, July 1971,41 (4), 608-619.

Lawder, E.A., Lower, K.D., Andrews, R.G., Sheman, E.A., \& Hill, J.G. A follow-up study of adoptions: post-placement functioning of adoption families. New York: Child Welfare League of America, 1969.

Lawton, J: \& Gross, S. "Review of psychiatric literature on adopted children." Archives of General Psychiatry, 1964, 11, 635-644.

Leitch, M. \& Escalona, S. "The reaction of infants to stress." In A. Freud, et al. (Eds.), Psychoanalytic Study of the Child. New York: International Universities Press, 1949, III/IV, 121-140.

Littner; N. Some traumatic effects of separation andpplacement. New York: Child Welfare League of America, 1971.

McDevitt, J. (Ed.) Separation-individuation. New York: Internation Universities Press, 1971.

Maas, $H$. "The young adult adjustment of twenty wartime residential nursery children." Child Welfare, 1963, 42 (2), 57-72:

Parnell, R.W. Behavior and physique: an introduction to practical and applied somatometry. London: Edward Arnold (Publishers) Ltd., 1958. 
Roback, A.A. The psychology of character. (3rd Ed.) London: Routledge \& Kegan Paul Ltd., 1952.

Rutter, M., Birch, H.G., Thomas, A. \& Chess, S. "Temperamental characteristics in infancy and the later development of behavioral disorders." British Journal of Psychiatry 1964, 110 (468), 651-661.

Rutter, M. Maternal deprivation reassessed, Harmondsworth, Middlesex, England: Penquin Books Ltd., 1972.

Rutter, M. "Parent-child separation: psychological effects on the children." Journal of Child Psychology and Psychiatry, 1971, 12, 233260 .

Schaffer, E.S. \& Bayley, N. "Maternal behavior, child behavior and their incorrelations from infancy through adolescent." Monograph of the Society for Research in Child Development, $196 \overline{3}, 28$ (3), Serial \# 87 .

Shaffer, H.R. "Activity level as a constitutional determinant of infantile reactions to deprivation." Child Development, 1966, 37, 595-602.

Skodak, M. \& Skeels, H.M. "A final follow-up study of one hundred adopted children." Leurnal of Genetic Psychology, 1949, 75, 85-125.

Skeels, H.M. "Effects of adoption on children from institutions." Children, 1965, 12, 33-34.

Skeels, H.M. "Adult status of children with contrasting early life experiences." Menographs of the Society for Research in Child Development, 1966, 31 (3), Serial \# 105 .

Stone, L.J., Smith, H.T., \& Murphy, L.B. (Eds.) The competant infant: research and commentary. New York: Basic Books, Inc., Publishers, 1973 .

Stott, L.H. Child development: an individual Tongitudinal approach. New York: Holt, Rinehart and Winston, Inc., 1967.

Taylor, A. "Deprived infants: potential for affective adjustment." American Journal of Orthopsychiatry, 1968, 31 (3), 835-845.

Tizard, J., Sinclair, I. \& Clarke, R.B.G. (Eds.) Varieties of residential experience. London and Boston: Routledge \& Kegan Paul, 1975.

Toussieng, P.W. "Thoughts regarding the etiology of psychological difficulties in adopted children," Child Welfare, 1962, 4l (2), 59-71. 
Walker, R.N. "Some temperament traits in children as viewed by their peers, their teachers, and their selves." Monograph of the Society for the Research in Child Development, $1967,32(6)$, Serial . if 114 .

Wenger, M.A. \& Ellington, M. "The measurement of autonomic balance in children: method and normative data. Psychosomatic Medicine, 5. 241-253.

Wenger, M.A. "The measurement of individual difference in autonomic balance." Esychosomatic Medicine, 1941, 3 , 427-434.

Westman, J. (Ed.) Individual differences in children. New York: John Wiley \& Sons, 1973.

Yarrow, L.J. The crucial nature of early experience. In D. Glass (Ed.), Environmental influcences: Biology and behavior series. New York: Rockefeller University Press and Russell Sage Foundation, 1968. 


\section{APPENDICES}

$-$ 


\section{APPENDIX A \\ PLACEABILITY BARRIERS}

\section{Placeability}

Now we come to placeability and we are trying to distinguish three factors: The child's physical condition, how the child copes socially, and the financial outlay necessary as a result of any of these conditions.

Physical characteristics: The child may have one or more physical characteristics which could negatively influence his/her placeability in an adoptive home or in long term foster care. Indicate by using the following scale the extent to which the physical condition would in your judgement, be a barrier to permanent placement. (Circle the appropriate number)

\section{Description}

1 No Barrier

2 Minimal Barrier

3 Minor Barrier

4 Moderate

5 Major

6 Severe
No noteworthy physical condition

A physically sound, but unappealing child

A single, non-debilitating impaiment, such as hare-lip, cleft palate, or crossed eyes. This condition can be corrected.

A single noticeable disabling impainnent which probably. can be corrected, such as some orthopedic or heart problem

A single noticeable major impairment which probably cannot be corrected, such as severe scarring, deafness, blindness, retarded looking; or two less disabling conditions such as allergic and orthopedic problems

Multiple gross non-correctable physical impairments, such as the blind, severely retarded child

This Appendix is. quoted verbatim from: Emlen, 1976, pp. 7.13-7.16 


\author{
APPENDIX A.I \\ PLACEABILITY BARRIERS (Cont.)
}

Coping: Does the child have any physical or behavioral characteristics that have affected his ability to cope socially and that might present a barrier to permanent planning? (Circie the appropriate number)

Category

1 ivone

2 Mininal

3 Minor

4 Moderate

5 Major

6 Severe

\section{Description}

This child has no noteworthy problem socially

A problem exists but it is not serious; it is probably temporary and will not require professional help. For example, the shy child.

A problem exists and càn probably be changed. This child may need some professional help. For example, the hyperactive child.

A more serious problem which would require professional help to alleviate. For example, the very anxious child, such as the chronic bedwetter and/or with other sleep disorders or who displays such behavior as lying or stealing

A serious social or emotional problem probably requiring long term professional attention. For example, the child with learning difficuities or behavioral problems such as sexual acting out, or the very withdrawn child

A child with a serious social or psychiatric problem. This condition is probably chronic and will require extensive, long-term psychiatric professional attention. For example, the schizophrenic child, or the autistic child

Financial Outlay: Forecast of the extent to which the financial outlay necessitated by the above physical or behavioral conditions would be a barrier to placing this child. Discount possible subsidies: (Circle the appropriate number)

Category

1 None

2 Minimal
Description

No extraordinary expense is anticipated for this child.

Little financial outlay beyond the normal expenses. For example, the child who needs glasses, or the "frail" child. 
APPENOIX A.2

PLACEABILITY் BARRIERS (Cont.)

Càtegory

3 Minor

4 Moderate

5 Major

6 Severe
Description

The financial outlay is minor and not likely to influence placement. For example, such conditions as diabetes or short term counseling

Moderate expense for counseling or behavioral problems or a single corrective surgery, or recurring expenses such as those usually required in orthodontia, hare-lip, or cleft palate surgery

Condition requiring one or more major surgical procedures; also repeated procedures such as those required for a dislocated hip or heart condition or frequent long-term psychiatric help

Single or multiple conditions requiring high financial outlay such as frequent long-term hospitalization, for such conditions as leukemia or cystic fibrosis

Overall Placeability: Considering physical characteristics, ability to cope, financial outlay, and any others which you believe are relevant, now make a global rating of the placeability of this child. Determine how easy or difficult it would be (or was) to make a permanent plan for this child. (Circle the appropriate number)

1. There will be (or were) no unusual problems in placing this child

2. There will be (or were) some difficulties in placing this child but they can be (or were) overcome.

3. It might be (or was) possible to place this child but it will require (or required) extensive effort and preparation.

4. The odds against being able to place this child are (or were) so great that it is (or was) questionable whether or not the attempt should be made.

5. There is almost no possibility that this child can be placed. 


\section{APPENDIX B \\ NINETEEN CHILD'S SELF-CONCEPT QUESTIONS}

\section{Question}

1. Child who plays with other children rather than fighting with them

2. Child who is able to build a block house

3. Child who socializes in a group rather than being alone

4. Child who has a happy disposition rather than a sad one

5. Child who does his work at school instead of playing

6. Child who is able to put together a puzzle

7. Child who plays with others at school rather than by himself

8. Child who pushes the wagon for others rather than riding in it

9. Child who plays with other children rather than being left out

10. Child who does his school work instead of distracting others

11. Child who has a laughing disposition rather than a crying one

12. Child who does his reading instead of getting distracted at school

13. Child who helps others up rather than being helped

14. Child who is able to do his school work

15. Child who gives piggyback rides rather than riding piggyback on other children

16. Child who has a happy disposition rather than an angry one

17. Child who identifies with nicesly dressed children in a group rather than being poorly dressed and alone

18. Child who receives praise from the teacher instead of scolding

19. Child who is happy more than sad 


\section{APPENDIX C \\ STEPWISE DISCRIMINANT ANALYSIS}

R.A. Fiser is usually credited with the first use of discriminant analys is as now commonly defined (Fisher, 1936).

Discriminant analys is has at least two common uses:

1) Given two or more groups and an unknown individual, the unknown individual is placed in a group with minimum probability of misclassification by developing a weighted sum of known variables so that differences among groups are maximized.

2) Given two or more groups of individuals, the variables are examined to determine which measures are the most useful in distinguishing among the groups.

The method of analys is is identical in the two cases but interpretation is different. In the first case, we are concenred about correctly identifying an unknown individual. In the second the identification is of little importance; the goal is to assess the importance of the discriminating variables. The sub-study was concerned with the second type. 
APPENDIX D

INITIAL STATUS AND HEALTH STATUS VARIABLES USEO

FOR CORRELATION MATRIX

\section{Initial Status}

1. Number of child's problems at first.

2. Child!s behavior in family at first(b)

3. Child's behavior outside home at first(b)

4. Change in child's home behavior (c)

5. Change in child's behavior outside home (c)

6. From beginning child made friends easily (d)

7. At first child didn't get along with siblings (d)

8. Adjustment to new child easy for parent (d)

9. More discipline problems at first (d)

10. Family's adjustment to the child at first (b)

\section{Health Status}

1. Child's health at first (b)

2. Change in child's health (c)

3. From first child was very healthy (d)

4. At first, child was sick a lot (d)

Scale: (b) $T=$ worse, to 10 = best

(c) 1 = worse; 2 = no change; $3=$ improved

(d) 1 = strongly disagree, to 4 = strongly agree 
APPENOIX 0.1

CHILD SELF-CONCEPT VARIABLES USED FOR CORRELATION

MATRIX ANO STEPWISE DISCRIMINANT

1. Child who plays with other children rather than fighting with them (a)

2. Child who is able to build a block house (a)

3. Child who socializes in a group rather than being alone (b)

4. Child who has a happy disposition rather than a sad one (a)

5. Child who is able to put together a puzzle (b)

6. Child who pushes the wagon for others rather than riding in it (b)

7. Child who plays with other children rather than being left out (b)

8. Child who helps others up' rather than being helped

9. Child who is able to do his school work (b)

10. Child who gives piggyback rides rather than riding piggyback on othęr. children (b)

Scale: (a) 1 = positive, 2 = negative

(b) 2 = positive, 1 = negative 


\section{APPENDIX E \\ PERMANENCY VARIABLES}

1. Parents understanding of the arrangement when the child first came (a)

2. Child's understanding of the present arrangement (a)

3. Parents understanding of the present arrangement (a)

4. Child is concerned about whether or not he or she will have to move again (a)

Scale: (a) $1=$ temporary, to $4=$ permanent

(b) 1 = strongly disagree, to 4 = strongly agree 


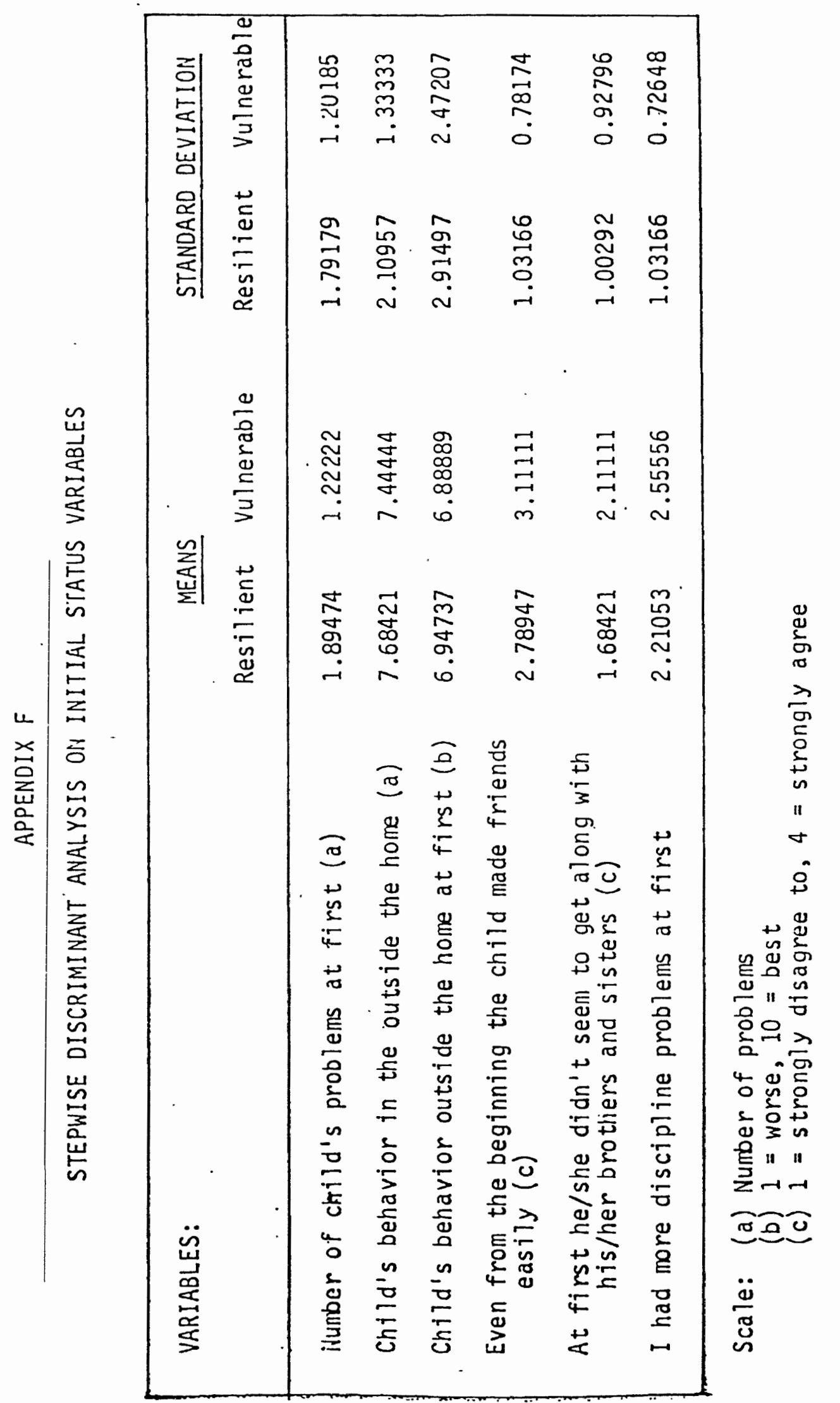




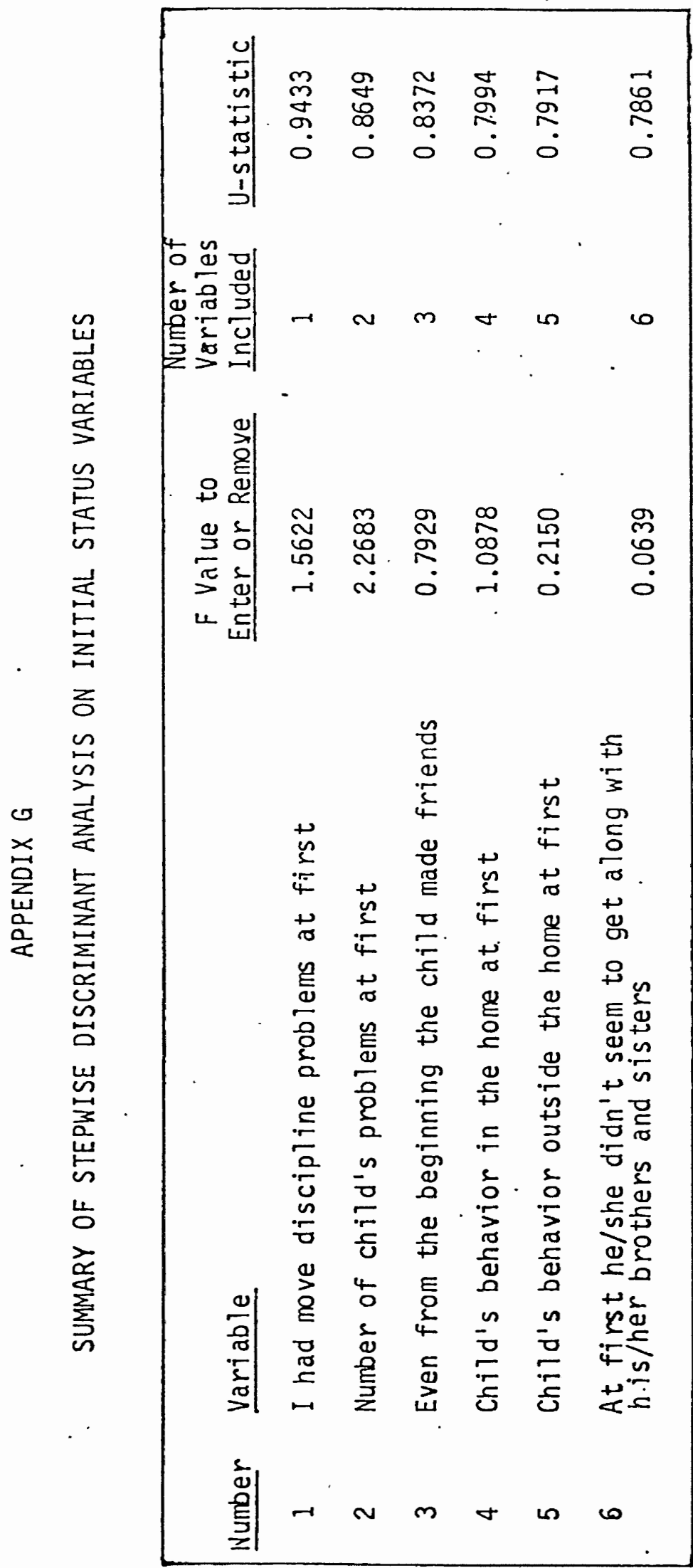



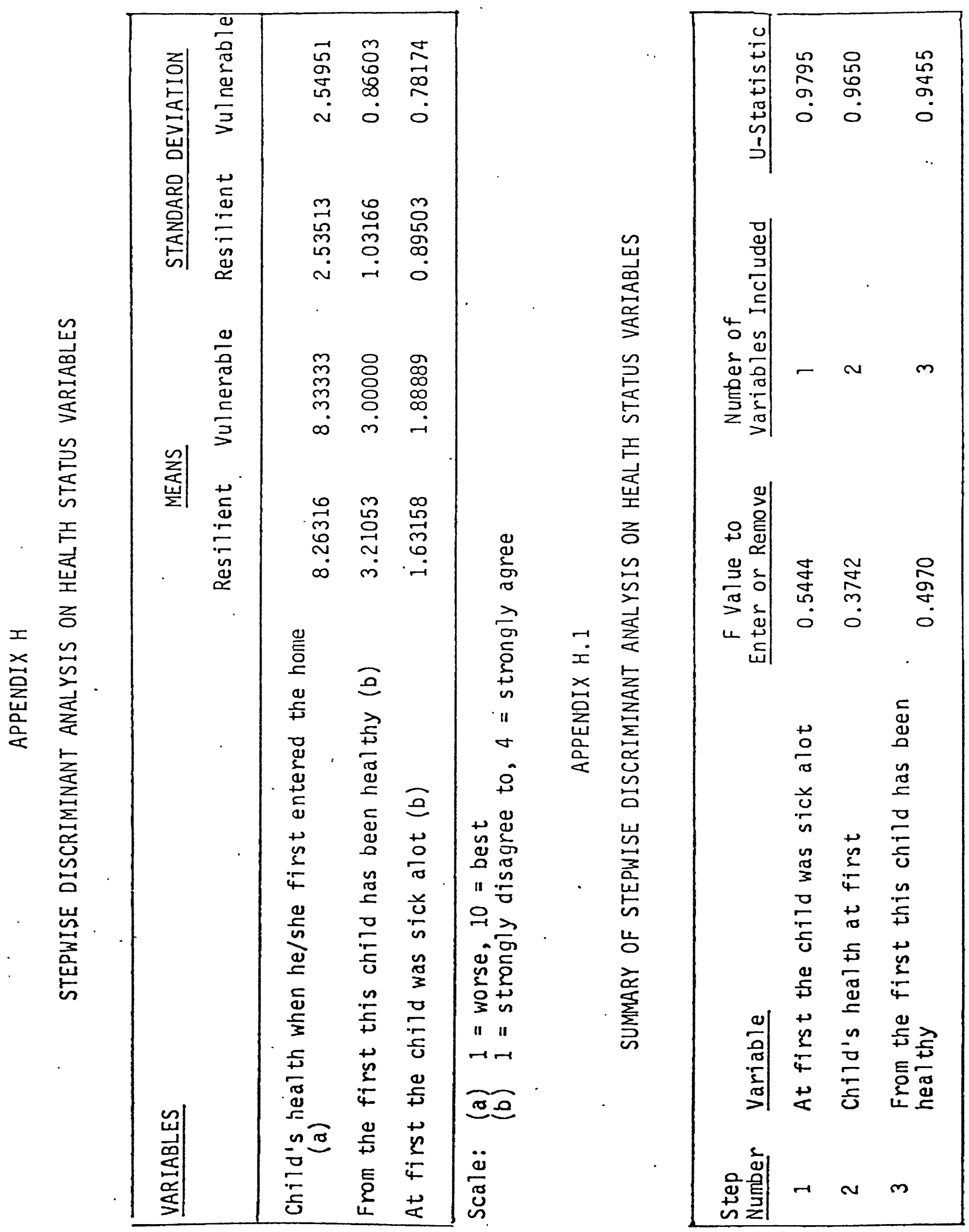


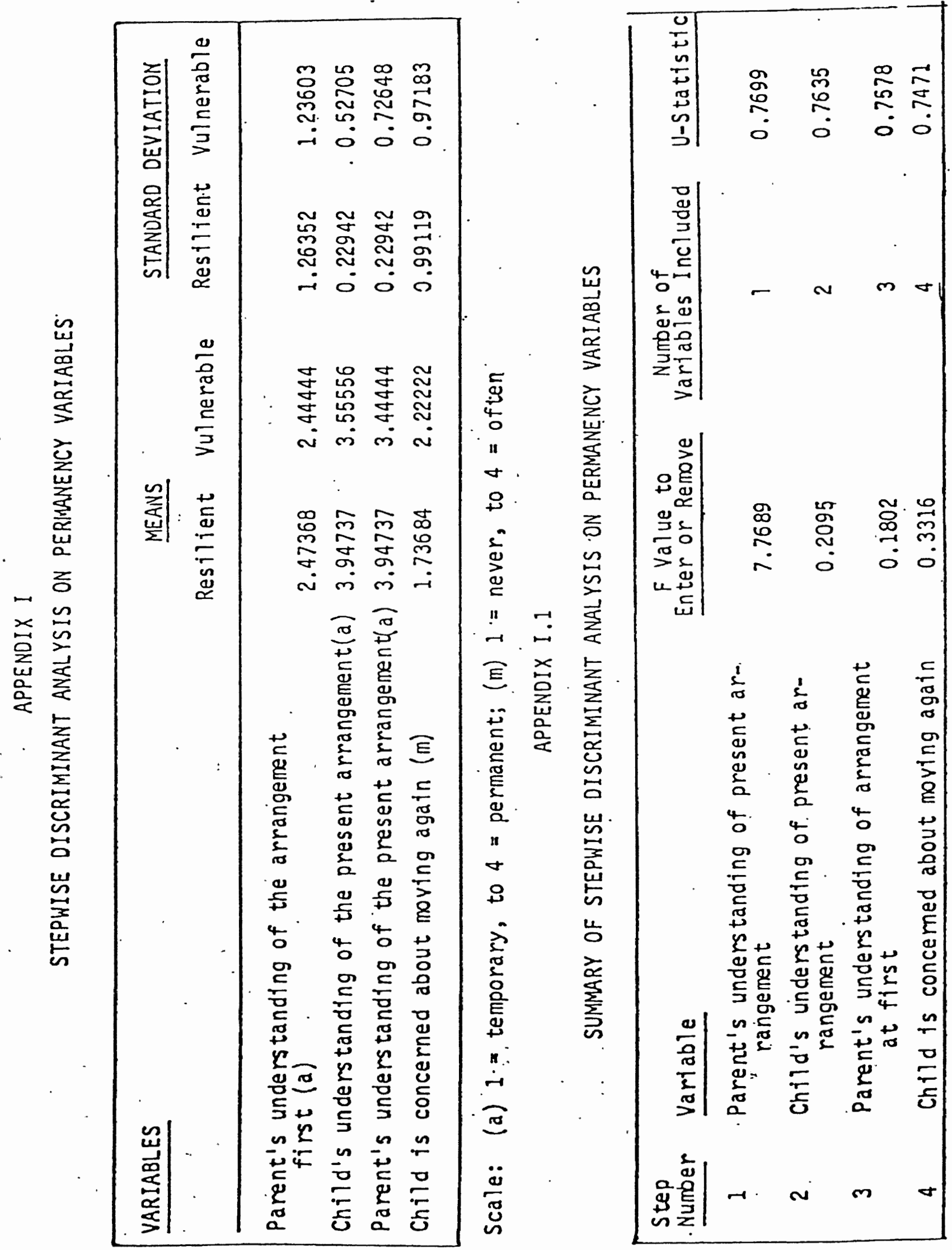

